\title{
Local COVID-19 Epicenter in Detroit Metropolitan Area Causing Profound and Pervasive Reorganization of Clinical, Educational, Research, and Financial Programs of a Large Academic Gastroenterology Division with a GI Fellowship and Primary Medical School Affiliation
}

\author{
Mitchell S. Cappell ${ }^{1,2}$
}

Received: 8 May 2020 / Accepted: 20 July 2021 / Published online: 13 September 2021

(c) The Author(s), under exclusive licence to Springer Science+Business Media, LLC, part of Springer Nature 2021

\begin{abstract}
Aim To report revolutionary reorganization of academic gastroenterology division from COVID-19 pandemic surge at metropolitan Detroit epicenter from 0 infected patients on March 9, 2020, to > 300 infected patients in hospital census in April 2020 and > 200 infected patients in April 2021.

Setting GI Division, William Beaumont Hospital, Royal Oak, has 36 GI clinical faculty; performs $>23,000$ endoscopies annually; fully accredited GI fellowship since 1973; employs $>400$ house staff annually since 1995; tertiary academic hospital; predominantly voluntary attendings; and primary teaching hospital, Oakland-University-Medical-School.

Methods This was a prospective study. Expert opinion. Personal experience includes Hospital GI chief $>14$ years until 2020; GI fellowship program director, several hospitals > 20 years; author of $>300$ publications in peer-reviewed GI journals; committee-member, Food-and-Drug-Administration-GI-Advisory Committee $>5$ years; and key hospital/medical school committee memberships. Computerized PubMed literature review was performed on hospital changes and pandemic. Study was exempted/approved by Hospital IRB, April 14, 2020.

Results Division reorganized patient care to add clinical capacity and minimize risks to staff of contracting COVID-19 infection. Affiliated medical school changes included: changing "live" to virtual lectures; canceling medical student GI electives; exempting medical students from treating COVID-19-infected patients; and graduating medical students on time despite partly missing clinical electives. Division was reorganized by changing "live" GI lectures to virtual lectures; four GI fellows temporarily reassigned as medical attendings supervising COVID-19-infected patients; temporarily mandated intubation of COVID-19-infected patients for esophagogastroduodenoscopy; postponing elective GI endoscopies; and reducing average number of endoscopies from 100 to 4 per weekday during pandemic peak! GI clinic visits reduced by half (postponing non-urgent visits), and physical visits replaced by virtual visits. Economic pandemic impact included temporary, hospital deficit subsequently relieved by federal grants; hospital employee terminations/furloughs; and severe temporary decline in GI practitioner's income during surge. Hospital temporarily enhanced security and gradually ameliorated facemask shortage. GI program director contacted GI fellows twice weekly to ameliorate pandemic-induced stress. Divisional parties held virtually. GI fellowship applicants interviewed virtually. Graduate medical education changes included weekly committee meetings to monitor pandemic-induced changes; program managers working from home; canceling ACGME annual fellowship survey, changing ACGME physical to virtual site visits; and changing national conventions from physical to virtual. Conclusion Reports profound and pervasive GI divisional changes to maximize clinical resources devoted to COVID19-infected patients and minimize risks of transmitting infection.
\end{abstract}

Keywords COVID-19 · Coronavirus · Pandemic · Gastroenterology fellowship · Academic gastroenterology · Gastroenterology clinical service $\cdot$ Clinical schedules

Extended author information available on the last page of the article 


\section{Introduction}

William Beaumont Hospital at Royal Oak, a very large $(1,200$ bed $)$, tertiary university hospital founded in 1953, has core academic commitments as the primary teaching hospital of Oakland-University-William-Beaumont-School-of-Medicine since founding the medical school $>10$ years ago; employs $>400$ house officers intraining annually for $>25$ years; and has continuously maintained an accredited GI fellowship since 1973. Hospital accolades include nursing magnet designation, tier 1 ( highest level) trauma center, and consistent ranking of Gastroenterology (GI) Division in the top 50 (top 1\%) of United States hospitals by U.S. News and World Report. The Hospital has been confronted with an unprecedented abrupt and prolonged surge in COVID-19 infections from 0 patients on March 9, 2020 [1], to $>300$ inpatients (> 25\% of hospital beds) in April 2020, and to $>200$ inpatients in April 2021 [2], with a cumulative total of about 13,000 distinct patients admitted to the Hospital with this infection within this time interval.

This work comprehensively reports the revolutionary reorganization of the gastroenterology, or gastrointestinal (GI) and hepatology, division in response to this pandemic, including both interim and up-to-date changes from March 2020-May 2021. To fully comprehend this reorganization, this work includes not only direct changes in the GI division, but indirect changes affecting the division from changes in the Department of Medicine, institutional Graduate Medical Education (GME) Department, Hospital administration, affiliated medical school, Accreditation Council for Graduate Medical Education (ACGME), professional GI/hepatology organizations, and governmental regulators. This work serves as a microcosm of reorganization throughout an academic hospital and is proposed as a representative model for reorganization of academic American GI divisions. This work may benefit clinical and academic GIs, hospital administrators, governmental healthcare regulators, medical ethicists, and medical historians in reporting profound and pervasive effects of the pandemic on GI. Literature review reveals little published data on how the pandemic impacted GI divisions. This current novel review is distinguished by its depth and comprehensiveness, including new, previously unreported data concerning reorganization, some of which might otherwise never be reported [3-8]. Analysis of this flagship Hospital of the Beaumont network may magnify pandemic effects because Beaumont provides tertiary care as a referral center for very sick patients with complicated diseases, including COVID-19-infected patients.

The division has a current complement of 6 GI fellows in total, and is currently fully accredited by ACGME without warnings or citations. The division maintains a large GI consultative and endoscopic clinical service, encompassing 36 GIs in private practice who are primarily affiliated with the Hospital and 3 full-time hospital-employed GIs; has a busy endoscopy suite performing $>23,000$ GI endoscopies annually before the pandemic; and maintains a liver transplant service for $>10$ years accredited by United Network Organ Sharing (UNOS) and approved for insurance reimbursement for liver transplantation by major medical insurers, including Medicare, Medicaid, and Blue Cross-Blue Shield of Michigan.

\section{Methods}

The author prospectively and continuously collected data from March 2020-May 2021 for this study. As GI fellowship program director of the GI fellowship from 2006 to current, the author is privy to internal memos, discussions, and committee meetings of the GI division, Department of Medicine, and senior hospital administrators, as well as Hospital publicity department, and news media. As co-director for clinical medicine of the second-year medical school course in GI and hepatology, the author is privy to medical school directives, committee meetings, and actions. The author is a member of the Hospital Graduate Medical Education (GME) Committee $>15$ years, and Hospital Endoscopy Committee for $>15$ years, and a member of the medical school Curriculum Committee for $>11$ years.

The investigator claims expertise in hospital administration by serving as Chief of GI at the Hospital from November 2006-September 2019, just before pandemic onset; as GI fellowship program director at various institutions for $>21$ years; as medical school GI and hepatology course co-director for $>11$ years; as a member of the Food and Drug Administration (FDA) Advisory Committee for GI drugs for 5 years; and as author of $>310$ publications in GI, including several publications on academic GI divisions or GI fellowships, and four publications on COVID-19 infection, listed below. The Hospital Institutional Review Board (IRB) approved this study, April 14, 2020.

\section{Review}

The clinical, teaching, research, and financial functions of this academic division were radically reorganized from March 2020-May 2021 because of the pandemic, as follows: 
Table 1 Changes in the affiliated medical school due to the pandemic

Medical school issue

First- and second-year (preclinical) medical school lectures

Laboratory sessions for first- and second-year medical school courses

Elective clinical rotations for fourth-year medical students

Third- or fourth-year medical students taking clinical rotations at other medical schools

Clinical clerkships or rotations at Beaumont for medical students visiting from other medical schools

Patients with active COVID-19 infections

Graduation of fourth-year medical students

Clinical clerkships

GI gastrointestinal

1. Medical School (Table 1).

\section{All Medical School Lectures for Preclinical Courses (Years} I and II) Changed from Live Lectures, in a Classroom Full of Medical Students, Seated Only 4 Feet Apart, to Exclusively Pre-Taped Audiovisual Lectures Delivered Remotely (Virtually) by Internet. William Beaumont Hospital at Royal Oak is one of 8 hospitals in the Beaumont Hospital network that are all located in the Greater metropolitan Detroit area, but as the primary teaching hospital and equal partner of the medical school at Oakland University, the Hospital provides most of the preclinical and clinical education for medical students. The medical school currently enrolls 125 medical students annually, for a full complement of 500 medical students, for all four medical school years. The first two (preclinical) years are taught almost entirely at the Oakland University campus in Rochester, Michigan, whereas the third and fourth (clinical) years are taught mostly on the clinical wards at William Beaumont Hospital at Royal Oak, with occasional clinical rotations held at William Beaumont Hospital at Troy, rare clinical electives held at other Beaumont network hospitals, and rare meetings at Oakland University at the medical school campus. Medical students rarely take clinical electives at other medical schools, outside the Hospital network, with permission from medical school
Changes during pandemic (time intervals)

Changed from "live" medical school lectures in classrooms to tapes of prior year lectures delivered virtually (March 2000-July 2000). Changed from tapes of prior year lectures delivered virtually to newly created taped lectures delivered virtually (August 2000-current)

Changed from six physical laboratory sessions in classrooms using actual pathologic and histologic specimens to questions virtually in real time led by a laboratory preceptor using virtually presented photographic images of specimens presented virtually by a laboratory preceptor. Students were able to ask preceptors virtual question in real time (March 2000-current)

Elective rotations in medical subspecialties, including GI, canceled (March-December 2020), resumed (January 2021-current)

Suspended (March 2020-February 2021), resumed (March 2021-current)

Suspended (March 2020-February 2021), resumed (March 2021-current)

Medical students exempted from treating patients with active COVID19 infection. Medical students can waive this exemption (March 2020-current)

Graduated on time despite missing small amounts of medical school electives during surge (May 2020 and May 2021)

Canceled GI or other clinical subspecialty electives (March-December 2020) administrators. Oakland University is located in Rochester, MI, about 20 miles away, or 30-45 min by car, from the Hospital at Royal Oak.

The medical school and teaching Hospital are both nonprofit, private, institutions, unaffiliated with municipal or state governments. Medical students normally spend most of their preclinical years attending required courses on major bodily organ systems, such as cardiology or GI, aside from attending several basic science courses, such as biochemistry. Faculty delivering clinical lectures in bodily organ system courses are mostly physicians employed full time at the Hospital, but some physicians are in private practice affiliated with the Hospital, whereas the basic science faculties for these courses are full-time employees of the Graduate School of Medical Sciences at Oakland University.

In mid-March 2020, Oakland University abruptly, emergently, and completely closed the medical school due to the suddenly raging pandemic in urban and suburban Detroit. After $96 \mathrm{~h}$ of intense deliberations, the medical school reopened, with all medical school lectures for the first two years changed in format from live lectures, presented in crowded lecture halls, to lectures presented virtually by audiovisual tapes remotely broadcast via the Internet to prevent medical students from contracting COVID-19 infection from being taught in crowded classrooms. Lectures were initially recycled from the prior 2019-2020 academic year (which had 
been routinely filmed when delivered live during the prior year), and which were broadcast on the Internet via a private, secure, audiovisual connection [9]. Colleges and universities, similarly, videotaped and transmitted course lectures for the same reasons.

As course co-director for the clinical GI and hepatology course, I was notified as course co-director on April 24,2020 , that the second-year medical school course in GI and hepatology would start on schedule in September 2020, but would use videotaped lectures rather than live lectures. It was not specified at the time whether the lectures for this course would be the recycled prior year taped lectures, as was occurring for courses running March-June 2020 or would involve newly videotaped lectures. From March-July 2020, I temporarily suspended preparing for the GI-hepatology course upcoming in September-October 2020, including postponing scheduling lecture dates and times, postponing recruiting GI and hepatology faculty for upcoming clinical lectures, revising the course curriculum, and meeting with the course co-director for basic science until this videotaping issue was resolved. First- and second-year medical school Curriculum Committee meetings, for course co-directors and student representatives, were still held monthly in AprilJuly 2020, but were limited by partial medical school closure. Committee meetings were held virtually by telephone or audiovisual conference via the Internet to prevent committee members from contracting COVID-19 infection by physically meeting in crowded classrooms.

Effective mid-July 2020, all future medical school courses changed from the recycled, previously taped, lectures, from the academic year 2019-2020, to newly created audiovisual lectures taped just before the onset of the upcoming 20202021 courses. Lecture formats were changed to comply with new curriculum guidelines recommended in spring 2020 by the Curriculum Committee. Questions posed by medical students attending the live lecture in 2019-2020 were eliminated; the newly taped audiovisual 2020 lectures were not videotaped before a live audience and, therefore, lacked questions.

In response to this decision in July 2020, audiovisual taping of new lectures was instituted abruptly and quickly. Medical school administration temporarily used WebEx and then another commercially available, remote access Internet system to broadcast videotaped lectures, but both formats proved cumbersome and impractical before the administration settled on audiovisual tapes using Microsoft Teams which functioned well. However, this new audiovisual taping of lectures was instituted during severe institutional budget cuts, in which information technologist (IT) personnel were cut by $20 \%$ (medical school administrators cut IT personnel from 40 to $32 \mathrm{~h}$ /week of work). Three clinical lectures scheduled for the renal and urology course running in August 2020, just before the GI and hepatology course, were abruptly canceled on the day of their lecture, without prior warning, because IT assistance was unavailable and the lecturers made technical mistakes using the Internet lecture system. These lectures were then successfully taped audiovisually and rebroadcast several days later.

The 30 "live" clinical lectures for the five-weeks-long GI and hepatology course presented during SeptemberOctober 2019, were replaced by newly created audiovisual tapes of lectures for September-October 2020. Canceling the previous format of live lectures freed-up the lecturer from a nearly 2-h round-trip commute from the Hospital to the medical school, which then became available for patient care. However, planning for the September-October 2020 GI and hepatology course encountered minor setbacks because audiovisual taping was supervised by academicians from the medical school, rather than IT personnel, with IT personnel only available for assistance by telephone by special request. This arrangement caused confusion and errors due to inadequate training of academicians. Only pre-taped lectures were used because "live" broadcasting of virtual lectures via Internet caused several lecture cancelations due to computer glitches. Ironically, three lectures presented by computer-savvy GI lecturers who felt they did not need IT support for audiovisual taping their lectures had to cancel their lectures because of computer glitches, whereas I, a rank amateur at IT, delivered my 8 lectures without computer glitches because I arranged for and relied on IT assistance.

The GI and hepatology course had 6 laboratory sessions, that each lasted one and a half to two hours, covering the subjects of upper GI anatomy, upper GI histology, lower GI anatomy, lower GI histology, hepatobiliary and pancreatic anatomy, and hepatobiliary and pancreatic histology. The presentation covered both normal and pathologic anatomy and histology. Before the pandemic, sessions were presented live in a classroom by a laboratory preceptor who demonstrated normal and pathologic finding using actual anatomic and histologic specimens. In 2020, these laboratory sessions were not conducted as physical sessions in classrooms due to the pandemic but were instead conducted as enhanced virtual sessions. Photographic images of anatomic specimens or microscopic histologic images were presented virtually by Internet accompanied by oral explanations of the illustrated slides. After presenting a slide, students were asked orally questions about the slide, which each student answered out loud. The answer was followed by the preceptor providing the correct answer with an explanation presented virtually. The laboratory session ended with questions by medical students answered by the laboratory preceptor which were transmitted live and virtually.

By January 2021, audiovisual recording of lectures was improved using simplified, automated audiovisual Internet connections via Microsoft Teams, rather than set-up of teleconferences by the lecturer, and computer glitches became 
rare. Microsoft Teams became the official commercial Website for audiovisual conferences for the medical school and Hospital in early 2021.

\section{Temporary Cancelation of Elective Clinical Rotations} for Third- and Fourth-Year Medical Students from March 2020-February 2021. Elective rotations in medical subspecialties, including clinical or research electives in GI, were canceled. Before the pandemic, one or two medical students usually attended GI monthly clinical electives in the Hospital. However, these electives were canceled during the early pandemic [10]. Substantial medical school closure for clinical rotations freed-up subspecialty clinicians from teaching responsibilities to medical students to permit the clinicians to devote more time for clinical care of COVID19 infected patients. All eligible fourth-year medical school students graduated as scheduled, on time, and were awarded their diplomas in May 2020, despite missing parts of several scheduled clinical rotations or electives due to the pandemic.
Clinical clerkships or electives for medical students visiting from other medical schools were suspended from March 2020-February 2021. Medical students at the Medical School were, likewise, prohibited from taking clinical electives at other medical schools during the same time period. Medical students were excused from evaluating and treating patients on Hospital wards who had active COVID-19 infection, unless students requested a waiver. These policies reduced the risk of medical students contracting COVID-19 infection.

Clerkships were substantially modified in March-June 2020 by use of objective structured clinical examinations (OSCEs) which were disseminated virtually using commercial platforms like WebEx. Substantial parts of the thirdyear clinical clerkships and the fourth-year clinical electives were changed to remote (virtual) learning. The diagnostic medicine clinical clerkship was transformed from a series of physical to virtual discussions. Teaching sessions on performing phlebotomy were canceled. The National Board of

Table 2 Changes in the GI division due to the pandemic

GI division issues
Roster of GI divisional clinic-academic lectures (weekly GI grand
rounds, biweekly program director rounds, weekly chief rounds, and
other lectures)
Lectures sponsored by professional GI organizations

Weekly medical grand rounds lectures

GI fellow schedule during COVID-19 surge

GI attendings reassignment from general GI consult service

Medical residents on GI elective monthly rotations

Advise GI consultants on conducting patient histories and physical examinations on suspected COVID-19-infected patients

New Medicare and Medicaid billing guidelines

Semi-elective and elective GI endoscopies

Patients undergoing EGD who have active COVID-19 infection

GI fellows performing GI endoscopy on their patients

GI clinic visits
Changes during pandemic (time intervals)

All "live" GI lectures canceled (March-August 2020); resumed as virtual GI lectures (September 2020-current)

GI division offered lectures by GI experts provided on complementary basis by GI professional organizations (especially the American College of Gastroenterology)

"Live" lectures canceled (March-August 2020); resumed as virtual lectures (September 2020-current)

Four GI fellows transferred from GI service to serve as medical attendings exclusively supervising medical residents and physician's assistants exclusively treating COVID-19-infected patients (April-May 2020). Resumed regular GI schedules (June 2020-on)

One GI attending transferred to cover GI consult service for exclusively COVID-19-infected patients (April-May 2020)

Medical resident elective rotations in GI consultative service suspended (March-July 2020); resumed (August 2020-current)

Rely on prior physical exam performed on same day by emergency room or medical attending. Obtain patient history and advise patient using telemedicine (April 2020-current)

Attendings allowed to bill for telemedicine (starting April 2020) Canceled (March-April 2020); or postponed (May 2020-current)

Mandatory endotracheal intubation and mechanical ventilation for EGD (March-April 2020). Consider elective intubation before EGD for patients who have active COVID-19 infection (May 2020-current)

GI fellows excused from performing GI endoscopies on their patients (March-April 2020). GI fellows expected to perform GI endoscopy on their patients (May 2020-current)

GI clinic visits scheduled only for relatively urgent indications, and postponed for relatively weak indications (March 2020-current). GI clinic visits conducted solely by telemedicine (March-June 2020). About half of GI clinic visits conducted physically in person, and about half conducted virtually (July 2020-current)

GI gastrointestinal 
Medical Examiners (NBME) test for emergency medicine was postponed until offered using remote proctoring.

\section{GI division reorganization (Table 2).}

1. GI Divisional Lectures Canceled. To reduce risks of pandemic dissemination and to conserve physician manpower for clinical duties, the normally robust schedule of academic lectures in the GI division was canceled from March-August 2020, including 1 weekly GI grand rounds, 1 weekly teaching conference with GI fellows and key clinical GI faculty, 2 weekly lectures conducted by the GI fellowship program director (me) with GI fellows, 1 monthly pathology lecture, 1 monthly GI journal club, and 1 quarterly GI morbidity and mortality conference. Cancelation of GI grand rounds freedup $1 \mathrm{~h}$ for each of about 25 GI clinical faculty attendees and reduced their risk of contracting COVID-19 infection while attending these lectures in crowded classrooms. Medical grand rounds was also canceled from March-August 2020, which freed-up $1 \mathrm{~h}$ weekly for each of about 125 grand rounds attendees, allowing them to devote more time to patient care, and minimizing their risks of contracting COVID-19 infection during grand rounds. GI and medical conferences were reinstituted September 2020, with conferences held remotely (virtually) by Microsoft Teams, without live attendance by lecturers or attendees. Outside speakers for GI conferences were uniformly postponed from March 2020-February 2021 and resumed in March 2021, with audiovisual conferencing by Microsoft Teams with the speaker located remotely at their local institution. To compensate for canceled divisional lectures, the GI division regularly and frequently offered GI fellows and medical residents rotating in the GI service, complementary lectures presented by national GI experts via Internet, sponsored by national GI or hepatology professional societies, especially the American College of Gastroenterology.

\section{GI Fellows Redeployed from GI Service to Supervise Newly Created Medical Wards Exclusively Devoted to COVID-19-In- fected Patients for April and May 2020. Before the pan-} demic, 3 GI teams manned 3 general GI teaching service teams per month performing GI consults, patient followups, and endoscopies, with each team containing 1 GI fellow supervised by $1 \mathrm{GI}$ attending; 1 further GI fellow was assigned to advanced endoscopy including diagnostic and therapeutic endoscopic retrograde cholangiopancreatography [ERCP] and diagnostic and therapeutic endoscopic ultrasound [EUS] supervised by GI attendings certified in advanced and therapeutic endoscopy; $1 \mathrm{GI}$ fellow assigned to hepatology/liver transplant service supervised by an attending hepatologist; and $1 \mathrm{GI}$ fellow assigned to GI electives in GI research or special clinical rotations, including pediatric
GI, colorectal surgery, or GI radiology under supervision by an attending. During April-May 2020, four GI fellows were reassigned as medical attendings at night to supervise physician assistants or medical residents working on newly created medical wards devoted exclusively to COVID-19 patients; this reassignment was legally valid because all GI fellows were licensed to practice independently as medical attendings after completing three years of medical residency before starting GI fellowship. One GI fellow covered hepatology/liver transplant service under supervision by an attending hepatologist; and 1 GI fellow covered GI consults, follow-ups, and endoscopies exclusively for staff and private patients with COVID-19 infection under supervision by a GI attending. In summary, 4 GI fellows were reassigned in April-May 2020 from covering exclusively GI services as GI fellows to supervise general medical wards as medical attendings for exclusively COVID-19 infected patients, and the 2 other GI fellows were covering the GI or hepatology consultative services treating mostly COVID-19-infected patients.

Rotation of GI fellows on general medicine wards exclusively treating COVID-19 patients was rescinded June 1, 2020, at which time all GI fellows reverted back to the pre-pandemic arrangement of covering only GI wards as GI fellows. This change became possible by the declining daily census of COVID-19-infected patients. A new wave of COVID-19 infection peaked in April 2021 with the number of COVID-19-infected in-hospital patients again reaching $>200[2])$.

\section{GI Attendings Reassigned from General GI Consultative} Services to GI Services for Exclusively COVID-19-Infected Patients. As aforementioned, in April-May 2020, the normal three GI consultative teams for general GI patients, each consisting of 1 GI fellow and 1 supervising GI attending per team, were disbanded and replaced by one GI consultative service designated exclusively for COVID-19-infected patients covered by 1 GI fellow supervised by 1 GI attending. One additional GI consultative team for overflow staff (non-private) GI patients (before the pandemic), normally manned by a physician's assistant and supervised by a GI attending was maintained, but also became substantially devoted to COVID-19-infected patients due to the pandemic surge. The hepatology consultative service was maintained with 1 GI fellow and 1 hepatology attending, but also substantially became a consultative service for COVID-19-infected patients. This GI attending reorganization during April-May 2020 reverted back to the pre-pandemic format for GI attendings in June 2020 because of markedly decreasing numbers of COVID-19-infected patients.

4. GI Electives for Medical Residents Discontinued. Before the pandemic, two or three medical residents rotated 
monthly on the GI consultative service under supervision by a GI fellow and GI attending. These residents were, however, pulled from the GI service to work on general medicine wards exclusively devoted to COVID-19-infected patients from March-June 2020. They did not rotate in the GI division during these months, but reverted back to their usual pre-pandemic clinical arrangement in July 2020. Medical resident research rotations in GI electives were suspended, March-December 2020 to accommodate the clinical need to treat COVID-19-infected patients.

\section{GI Consultants Directed to Alter Patient Interviews and} Physical Examinations of COVID-19-Infected Patients. In March 2020, the Hospital Physician-in-Chief directed all subspecialty consultants, including GI consultants, to maintain 6 feet distance from patients with confirmed or suspected COVID-19 infection, unless absolutely necessary, to minimize consultant risks. Patients were interviewed by telemedicine, either by telephone or audiovisual conference. Consultants could avoid physical examinations by relying on physical examinations performed earlier on the same day by emergency room or medical ward attendings. The Centers for Medicare and Medicaid Services (CMS) established in April 2020 a new billing code to reimburse physicians for telemedicine [11].

\section{Postponement of Elective or Semi-Elective GI Endosco-}

pies. The Hospital postponed all elective and semi-elective GI endoscopies, whether outpatient or inpatient, regardless of COVID-19 status, starting late March 2020 until June 1, 2020 due to insufficient Hospital supplies of personal protective equipment, especially N95 masks, and to reduce risks to endoscopy personnel of contracting COVID-19 infection from infected patients undergoing endoscopy. Patients with urgent or emergent indications still underwent GI endoscopy. Attending GIs could appeal postponed in-hospital endoscopies to the Chief of GI when there was a compelling need for undergoing endoscopy. A survey of 11 GI endoscopy suites in the New York metropolitan area reported a 90\% reduction of GI endoscopies during the early pandemic [12]. At the Hospital endoscopy suite, the decline was even more drastic; the average number of daily GI endoscopies declined from the usual rate of 100 to only 4 per weekday [13]!

The endoscopy suite did not routinely screen patients for COVID-19 infection before performing endoscopy until July 2020, although patients undergoing elective surgery were screened for this infection several months earlier. Patients with known COVID-19 infection undergoing esophagogastroduodenoscopy (EGD) required prophylactic endotracheal intubation and mechanical ventilation from mid-March until April 17, 2020, to protect endoscopy personnel from contracting COVID-19 infection. An association of COVID-19 infection with diarrhea and finding of infectious COVID-19 particles in stool [14], raised the possibility of transmitting COVID-19 infection to endoscopy personnel during colonoscopy and whether prophylactic endotracheal intubation and artificial mechanical ventilation was warranted for COVID-19-infected patients undergoing colonoscopy.

Mandatory intubation for EGDs performed on inpatients with active COVID-19 infection was rescinded and made voluntary after four national/international GI and hepatology professional societies issued a joint statement that endotracheal intubation and mechanical ventilation in such situations was not mandatory [15]. GI endoscopies performed on COVID-19-infected patients were, if possible, scheduled as the last procedure of the day in a given endoscopy room to minimize risks of viral contamination of endoscopy rooms. This endoscopic strategy had been previously applied for HIV-seropositive patients.

In March-May 2020, all GI fellows could excuse themselves from performing GI endoscopies on their patients and have the GI attending perform endoscopy alone without the GI fellow. This policy was changed in June 2020 to have GI fellows assist in GI endoscopies performed on their patients. The GI division reduced the minimum threshold number of specialized GI endoscopies during the three year fellowship for certification for specialized endoscopies (e.g., ERCP) to accommodate the decrease in GI endoscopy volume from March-May 2020.

7. GI Clinic Visits Restricted to Outpatients with Relatively Urgent GI Complaints. The ambulatory (continuity) GI fellows' clinic operates two half days per week, with each GI clinic staffed by 3 GI fellows supervised by 1 GI attending. Before the pandemic, patients were normally seen for mild-to-moderate, acute or chronic, GI disorders. Each GI fellow typically had 8-9 patients scheduled per clinic and saw about 6 patients per clinic because of 2 or 3 "no-shows," for an average of 36 GI clinic visits per week ( 6 clinic visits per GI fellow $\times 3$ GI fellows per clinic $\times 2$ clinics per week). Before the pandemic, medical attendings and medical residents could schedule patients for GI clinic without GI fellow approval, but with the pandemic the GI service instituted in March 2020 prescreening of patients for upcoming GI clinics. Fellows reviewed patients' medical records and briefly contacted patients by telephone to determine when a patient should be seen in GI clinic. Patients with relatively urgent indications were scheduled for early GI clinic visits, but other patients had their GI clinic visits postponed for 8 weeks or more. Prescreening reduced the total number of GI clinic visits per week from about 36 to 18 patients, to reduce the stress on the GI service from overload with COVID-19 infected patients.

8. GI Clinic Visits Conducted Virtually by Telemedicine. Before the pandemic, patients were uniformly seen in person 
in GI clinic in private examining rooms. GI fellows normally interviewed patients face to face, performed physical examinations on their patients; and returned with their supervisory GI attending to review the patients' GI condition and discuss their recommendations with patients. During the early COVID-19 surge from March-June 2020, all clinic visits became virtual via telemedicine: patients were contacted, interviewed, received recommendations, ordered to undergo tests, and prescribed medicines by videoconference or telephone. In person (live) GI clinic visits were reinstituted starting July 2020, but GI telemedicine clinic visits were also continued. Currently, in June 2021, about half of GI clinic visits are live in-person, and about half are virtual by telemedicine. Patients who are sicker and have urgent indications for clinic visits are seen "live," whereas patients who are less sick and have more elective indications for clinic visits are seen by telemedicine. Due to the pandemic, patients seen in person at GI clinic are not permitted to be accompanied by a companion unless medically necessary (e.g., patient has dementia).

\section{Amelioration of Long Delays in Outpatient GI Clinic Endos-} copies. Outpatient endoscopies have faced long delays because of less slots in the endoscopy suite due to increased turnaround room cleaning times between endoscopies due to the pandemic, $15 \%$ decrease in endoscopy nurses, and decreases in attending anesthesiologists and nurse-anesthetists. The Hospital has encouraged private GI attendings and a hospital-employed GI attending (me) to perform extra GI endoscopy sessions to decrease the waiting list for ambulatory endoscopies of GI clinic patients. GI clinic patients now have a half-day endoscopy block per week in the hospital endoscopy suite and a full-day endoscopy block per week in a nearby hospital-owned ambulatory endoscopy center to shorten the endoscopy waiting list for clinic endoscopies. I have been performing ambulatory endoscopies with GI fellows during these block times.

\section{Replacement of "Live" Interviews with Virtual Interviews} for GI Fellowship Applicants. Interviews of GI fellowship applicants were changed in 2020 from physical hospital interview visits to virtual interviews by Internet to reduce the risks of COVID-19 transmission during the pandemic. The Hospital GI fellowship received a record number (400 applications) in 2020, possibly because of instituting the virtual interview process. All applicants selected for virtual interviews accepted interviews, as opposed to a dropout rate of about $20 \%$ in prior years using physical interviews. These twin phenomena were attributed to greatly reduced investment in time and money by interviewees for virtual interviews due to eliminating the time and cost of physical interviews, including round-trip airplane travel and overnight stay at a hotel.
The virtual interview process closely simulates the prior physical interview process before the pandemic, by having individual interviews conducted by Internet, by supplying a taped audiovisual tour of hospital facilities produced by the GI fellows under attending supervision, by providing a detailed list of the GI fellowship monthly schedule and employment conditions via the Internet, and by arranging for applicants to confidentially meet current GI fellows via Microsoft Teams, with access restricted to exclude GI attendings to maintain meeting confidentiality [16]. The Alliance for Academic Internal Medicine recently recommended that the fellowship interview process should also be entirely virtual for 2021 .

11. GI Conference Room in Endoscopy Suite Previously Used by GI Fellows and Key GI Faculty for Meetings Requisitioned by GI Endoscopy Nurses and Technicians for Use as an Accessory Lounge. Physical space in the GI endoscopy suite is valuable and scarce because of the high earning potential of endoscopy rooms due to the high room charge per endoscopic procedure. Indeed, the GI endoscopy suite earns the Hospital nearly 30 million dollars in revenue from performing about 23,000 endoscopies annually. Before the pandemic, the endoscopy suite had a small lounge for endoscopy nurses and technicians to use for lunch and job breaks, and had a separate small conference room for GI physicians for lectures and meetings. After the pandemic began, the Hospital requisitioned this GI physician conference room to provide endoscopy nurses and technicians enough space to ensure six feet of distance between individuals during lunch or work breaks. This directive severely curtailed GI physician access to the GI conference room. This directive is still in effect in June 2021.

III. Consequences of Pandemic to the United States Economy in General, and to Hospital and Hospital Physicians' Income in Particular (Table 3).

1. Pandemic Caused an Abrupt, Massive ( $31.4 \%)$, Contrac-
tion of Gross Domestic Product (GDP) in the Second Quarter of 2020. Pandemic caused massive layoffs with the unemployment rate soaring to $14.8 \%$ in April 2020, and caused massive temporary business closures due to stay-at-home policies [17]. In response, the United States Federal Reserve Bank drastically lowered interest rates to stimulate the housing market and other interest-rate-sensitive industries, and the federal government passed four large stimulus packages in 2020 and early 2021 to provide substantial financial relief to families and businesses impacted by the pandemic and to stimulate the economy [18]. These interventions caused a moderate economic recovery from July 2020May 2021, reflected by improvements in GDP, decreasing 
Table 3 Economic impact of pandemic to American economy, Beaumont Hospital, GI division, and GI physicians

\begin{tabular}{|c|c|}
\hline Economic issues & Changes (with time intervals) \\
\hline Contraction of American economy & $\begin{array}{l}\text { Severe unemployment (up to } 14.8 \% \text { ) and severe decline in gross } \\
\text { domestic product ( } 31.4 \% \text { ) (April-June 2020). Slow gradual economic } \\
\text { recovery thereafter (July 2020-current) }\end{array}$ \\
\hline Severe Hospital deficit & $\begin{array}{l}\text { About } 500 \text { million dollars hospital deficit subsidized by federal bonus } \\
\text { payments (March-December 2020) }\end{array}$ \\
\hline Hospital layoffs and furloughs & $\begin{array}{l}\text { About } 7 \% \text { of employees laid off or furloughed (April-June 2020). } \\
\text { Gradual recovery of employment (July 2020-current) }\end{array}$ \\
\hline Decline in income of GI practitioners & $\begin{array}{l}\text { Only } 4 \% \text { rate of normal pre-pandemic performance by GIs of endos- } \\
\text { copy at Beaumont (April 2020). Gradual slow recovery (May } \\
2020 \text {-current) }\end{array}$ \\
\hline Medical school tuition & $\begin{array}{l}\$ 1,000 \text { reduction in medical school tuition for all students for years } \\
\text { I-IV due to substitution of virtual for physical lectures (academic year } \\
2020-2021 \text { ) }\end{array}$ \\
\hline GI attendings in private practice & $\begin{array}{l}\text { Received clinical income bonus from federal government amounting to } \\
\text { several percent of annual income (March-May 2020) }\end{array}$ \\
\hline Hospital house staff bonus payment & $\begin{array}{l}\text { Received } \$ 1,000 \text { bonus because of extra work and extra risks during } \\
\text { pandemic (June 2020) }\end{array}$ \\
\hline $\begin{array}{l}\text { Hospital bonus payment to house staff and attendings employed full } \\
\text { time by Hospital }\end{array}$ & $\begin{array}{l}\text { Received } \$ 1,000 \text { bonus because of extra work and extra risks during } \\
\text { pandemic (November 2020) }\end{array}$ \\
\hline One complementary lunch per week for four consecutive weeks & $\begin{array}{l}\text { All clinical employees received this gesture from hospital administra- } \\
\text { tion for their hard work during pandemic (April-May 2021) }\end{array}$ \\
\hline $\begin{array}{l}\text { Exclusive contract of Hospital with anesthesiology group terminated } \\
\text { after }>20 \text { years of employment }\end{array}$ & $\begin{array}{l}\text { Affected Hospital efficiency during pandemic even though unrelated to } \\
\text { pandemic (contract terminated January 1, 2021). Effects on Hospital } \\
\text { gradually decreased (January-April 2021) }\end{array}$ \\
\hline Most Hospital librarians terminated & Occurred in stages (October 2019-January 2021) \\
\hline Hospital network raised minimum wage of all employees to $\$ 15.00 / \mathrm{hr}$ & $\begin{array}{l}\text { Significantly raised salaries of lowest paid hospital workers (custodial } \\
\text { staff). Rationale for raise is to compensate workers for working under } \\
\text { greater stress due to pandemic }\end{array}$ \\
\hline
\end{tabular}

GI gastrointestinal

unemployment, decreasing pace of layoffs, and an improving economic outlook. This provided the financial background in which the GI physicians, GI division, and Hospital struggled financially, as follows.

2. Severe Hospital Deficit Early in Pandemic. To accommodate the surge of COVID-19-infected patients, the Hospital nearly ceased performing elective surgery or endoscopy; the number of surgeries declined by $>90 \%$, and the number of GI endoscopies declined by $96 \%$ from baseline before the pandemic. Indeed, most hospital operating rooms in MarchMay 2020 were transformed into intensive care unit (ICU) rooms to accommodate the explosive growth of patients infected with COVID-19 needing ICU beds after undergoing endotracheal intubation and artificial mechanical ventilation. This surge resulted in $>25 \%$ of hospital beds filled with COVID-19 patients, even though the hospital census was reduced to $<55 \%$ of capacity due to decreased elective admissions for patients with other illnesses. These twin effects peaked in May 2020. Before the pandemic, the Hospital had consistently run at $>90 \%$ of bed capacity.
This overall decrease in hospital admissions, surgeries, procedures, and emergency room visits together with increased hospital expenses incurred by purchasing massive quantities of personal protective equipment (PPE), which rose sixfold in price early in the COVID-19 pandemic, and increased purchases of mechanical ventilators caused an abrupt 278.4 million dollar loss for the January-March 2020 quarter compared to a profit of 129.1 million dollars during the same quarter in 2019. In March and April, 2020, the federal government granted 75 million dollars to the Hospital, as part of a COVID-19 stimulus package, to partly compensate the Hospital for this loss. The deficit in the next several quarters was projected to be approximately 500 million dollars [18], but the Hospital received altogether about 500 million dollars in four extraordinary bonus payments from the federal government, via Medicare and Medicaid, in 2020-2021 due to the pandemic [19].

\section{Hospital Layoffs and Furloughs Due to Large Deficit During} Early Pandemic. Due to the deficit, the Hospital on April 21, 2020, terminated 450 hospital employees and temporarily furloughed 2,500 (>7\% of) its employees, mostly hospital 
administrative staff, other employees not directly performing patient care, and employees whose clinical departments were temporarily closed due to the pandemic, such as cardiac rehabilitation [20-22]. Additionally, Beaumont Hospital at Wayne, which had been transformed in March 2020 to an exclusively COVID-19 patient hospital, closed indefinitely on April 24, 2020.

The GI division permanently lost one half-time divisional administrative secretary and temporarily furloughed one 0.4 full-time equivalent GI fellowship program manager/coordinator, who represented nearly all the support staff for the Division. The GI endoscopy unit furloughed seven (10\% of) GI endoscopy nurses and terminated all but one of the GI endoscopy schedulers. Furloughs went into effect immediately. Furloughed employees lost their salaries for 60 days, but the hospital maintained their medical insurance during the furlough, and these employees were allowed to apply for and receive unemployment insurance during their furlough. Furloughed employees were rehired by June 30, 2020. Other hospital systems in the greater metropolitan Detroit area, including Detroit Medical Center, Trinity Health Michigan, and Henry Ford Health System, announced similar employee furloughs or terminations in April 2020 [23]. Beginning December 2020 the Hospital encountered challenges in recruiting new endoscopy nurses to replace the furloughed nurses or other nurses leaving during the pandemic.

4. Immense Temporary Decline of GI Physician Income. The income of GI attendings in private practice declined dramatically due to precipitous declines in GI office visits and elective GI endoscopies during March-June 2020. For example, my crude, oral survey of five GI colleagues in private practice revealed that their total revenues declined by $>80 \%$ during the pandemic peak in late April 2020. Similarly, in a poll conducted in April 2020, 97\% of dentists reported that their offices were closed except for dental emergencies, and their monthly income declined by $\geq 95 \%$ [24]. GI subspecialists and dentists may share high personal risks of contracting COVID-19 infection from examining and working within oral cavities of COVID-19-infected patients during EGD or dental work, respectively, or contrariwise may share high potential risks of transmitting infection from themselves to uninfected patients via this close oral contact. The severity of economic damage to GI practitioners and GI divisions largely depends upon pandemic severity and duration. The surge temporarily threatened the economic viability of GIs in private practice, and potentially threatened the salaries of hospital-employed GIs. GI practice, training, education, and research was undermined by the Hospital financial crisis during the pandemic surge.

The immense decline in GI income started to reverse about July 2020 with substantial resumption of GI endoscopy. For example, the rate of performing GI endoscopy recovered from $<4 \%$ of baseline to about $50 \%$ by November 2020. Widespread vaccination of the American population against COVID-19 infection in 2021 is bringing recovery to the general American economy, and to the GI market in particular.

5. Medical Student Tuition Reduction for 2020-2021. The medical school awarded all medical students, for all years (1-4), a $\$ 1,000.00$ discount in tuition for academic year 2020-2021 in recognition of the hardships they faced in attending classes due to the pandemic. The medical students appreciated this symbolic gesture.

6. GI Attendings in Private Practice Received a Clinical Bonus in May 2020 From The Federal Government Amounting to Several Percent of Their Clinical Earnings for 2019. This bonus was given to compensate physicians for their large loss in clinical income during the pandemic, especially during the surge in March-May 2020. This compensation was based on physician compensation from Medicaid and Medicare, according to the physician's 2019 tax return.

7. Hospital Residents and Fellows, Including GI Fellows, Successfully Petitioned Hospital Administration to Receive a Modest Bonus to Compensate Them for Their Extra Clinical Work (and increased COVID-19 risks) performed during March-May 2020 because of the pandemic. Residents requested a clinical bonus after medical attendings and GI attendings in private practice received substantial clinical bonuses from the federal government (item III.6) and after the hospital itself received large bonuses from the federal government (item III.1) because of the pandemic. This petition was unanimously supported by the institutional GME Committee and its administrators, Dr. Ronald Fringer, and Dr. Jeffrey Devries, who convinced the Hospital to grant all house staff, including GI fellows, a bonus of $\$ 1,000.00$ per individual in June 2020 for their extra clinical work in March-May 2020.

In November 2020, hospital administration granted another $\$ 1,000.00$ bonus to all residents and fellows, including GI fellows, to recognize their continuing help in performing extra clinical work due to the pandemic [25]. This time Hospital administration also granted a $\$ 1,000.00$ clinical bonus to all clinical, full-time employed, attendings for their extra work during the pandemic and in light of the approximately 500 million dollars cumulative bonuses awarded to the Hospital by the federal government during the pandemic.

8. Beaumont Hospital at Royal Oak Provided One Complementary Lunch Per Week for Four Consecutive Weeks in April-May 2021 to All Hospital Physicians. This symbolic gesture by Hospital administration recognized the hard work 
of Hospital physicians because of the pandemic and was appreciated by the physicians.

\section{Hospital Terminated Exclusive Contract with Hospital} Anesthesiology Group During Pandemic After $>20$ Years of Affiliation. The Hospital network terminated a longstanding contract with the academic anesthesiology group at Beaumont Hospital on December 31, 2020, and hired another anesthesiology group starting January 1, 2021 to reduce costs. About one half of affiliated anesthesiologists left with contract termination, and about one half of nurseanesthetists employed by the Hospital also left with the anesthesiologists. This change proved somewhat controversial because it occurred during the COVID-19 pandemic and resulted in temporary significant difficulties in filling anesthesiology departmental vacancies that caused cancelations in endoscopies because of a temporary shortage of anesthesiologists supervising GI endoscopy cases.

10. Most Hospital Librarians Terminated. In October 2019, several months before the pandemic began, the number of librarians and library technicians employed at the 8 Beaumont Hospitals was reduced from 14 to 9 full-time equivalent positions to reduce hospital costs. With the pandemic onset, all 9 remaining librarians/library technicians were furloughed without pay, March-September 1, 2020, but with health benefits maintained and with the ability to apply for and receive unemployment insurance during the furlough. During this period the hospital library at Royal Oak remained open to physicians and other healthcare professionals without librarians. In September 2020, five librarians were reinstated, and the other four librarians were terminated. Starting September 2020 librarians were available virtually by Internet, but were not physically present at hospital libraries. Virtual access to librarians was inconvenient and cumbersome for clinicians and researchers due to lack of live, face-to-face interactions. The five librarians returned physically to work in the hospital library around January 2021. All librarians were transferred to the Hospital at Royal Oak rather than spread among network hospitals, as before the pandemic. Centralization of librarians at the Royal Oak campus is reasonable because of the high demand for library services at this Hospital compared to the low demand at the other Beaumont network hospitals.

\section{In 2020 During the Pandemic, the Hospital Network} Raised the Minimum Wage of All Employees to $\$ 15.00 / \mathrm{hr}$ [18]. This constituted a very large raise for the lowest paid hospital workers, such as custodial workers, who previously earned about $\$ 11.00 / \mathrm{hr}$. This raise was designed to compensate low paid hospital workers for working under the stress of the pandemic. This raise did not affect the salaries of clinical employees in the GI division who already earned more than the new minimum wage.

12. Hospital Administration Approved Voluntary Annual Hospital Contribution to $401 \mathrm{~K}$ Retirement Fund to Hospital-Employed Physicians Every year the Hospital decides whether to fund a voluntary retirement benefit to employed physicians of about six thousand dollars per physician's retirement account. Most years the Hospital funds this annual contribution, but the Hospital has occasionally not funded this contribution due to budgetary shortfalls. In 2020 and 2021 the Hospital voluntarily contributed to this fund. This contribution likely reflects that Hospital administration felt that the physicians deserved this voluntary contribution for their hard work in 2020 and 2021, and that the Hospital is now doing well financially, with a reported profit margin of $4 \%$ in 2020 .

\section{Hospital-Wide Changes (Table 4).}

1. Cleaning Solution and Cleaning Regimens Used Between Endoscopy Cases Changed During Pandemic to Provide Longer Cleaning with More Intensely Viricidal Chemicals. This change increased delays (longer turnover time) between endoscopies and diminished the maximal capacity of cases that could be performed per day per endoscopy room by about $10 \%$. The maximal number of endoscopy cases per day was also decreased because of significant shortages of endoscopy nurses and anesthesiologists. The Hospital also changed the type of disposable gloves used in the endoscopy suite and other procedure rooms (such as the cardiac catheter lab) to thicker gloves to reduce the risk of contaminating the hands of endoscopists and other proceduralists with COVID-19 infection. The Hospital also stocked the endoscopy suite and other interventional suites with disposable face masks with attached goggles to protect the eyes of endoscopists or other proceduralists from being contaminated with COVID-19 infection during procedures (see IV.8).

\section{Hand Washing Using Enhanced Viricidal Solutions and} Use of Cleaned Scrubs Throughout Hospital. To prevent infection, the Hospital installed new soap dispensers containing chemicals designed to kill $99.9 \%$ of viruses, including COVID-19, next to all sinks in all hospital bathrooms, laboratory rooms, and kitchens. Also, hospital clerks at all hospital entrances distributed an antiviral cleansing solution to hospital employees and hospital visitors to clean and disinfect their hands. During April-May 2020, hospital physicians were encouraged to change daily into freshly laundered scrubs rather than wear their civilian attire within the hospital. This represented a radical change in Hospital policy; 
Table 4 Hospital-wide changes due to pandemic

\begin{tabular}{|c|c|}
\hline Hospital-wide issues & Changes (time intervals) \\
\hline Cleaning solutions and regimens for GI endoscopy equipment & $\begin{array}{l}\text { Changed to provide longer cleaning time with more intensely viricidal solu- } \\
\text { tions against COVID-19 (April 2020-current) }\end{array}$ \\
\hline Hospital requested full-time clinical employees to defer vacations & $\begin{array}{l}\text { Hospital request due to staff physicians shortages during pandemic peak } \\
\text { (April 2020) }\end{array}$ \\
\hline Hospital security & $\begin{array}{l}\text { Security greatly enhanced. Patient visitors barred entry to Hospital due } \\
\text { to pandemic (March-July 2020). Gradually loosened hospital security } \\
\text { (August 2020-current) }\end{array}$ \\
\hline Annual physician mandatory education & $\begin{array}{l}\text { COVID-19 module consisting of } 12 \text { slides and a brief post-module quiz } \\
\text { added to annual mandatory physician education (March-May 2021) }\end{array}$ \\
\hline Hospital cafeteria & $\begin{array}{l}\text { Change to offering disposable plastic (silverware, plates, and lunchboxes) } \\
\text { during pandemic to reduce risks of COVID-19 transmission (April } \\
\text { 2020-current) }\end{array}$ \\
\hline Hospital cafeteria & $\begin{array}{l}\text { Plastic (Lucite) barriers erected between cafeteria customers and servers to } \\
\text { reduce risks of COVID-19 virus transmission }\end{array}$ \\
\hline COVID-19 testing & $\begin{array}{l}\text { With time became progressively more available, with faster turnaround time, } \\
\text { and greater accuracy (April 2020-current) }\end{array}$ \\
\hline Face masks & $\begin{array}{l}\text { With time highly effective face masks (N95 and KN95) became more avail- } \\
\text { able to Hospital physicians (June 2020-current) }\end{array}$ \\
\hline Hand washing & $\begin{array}{l}\text { Installed viricidal dispensers near all sinks in Hospital. Hospital changed to } \\
\text { enhance viricidal solution in dispensers (April 2020-current) }\end{array}$ \\
\hline Vaccination against COVID-19 infection & $\begin{array}{l}\text { Hospital started vaccinating employed physicians using Pfizer-BioNTech } \\
\text { vaccine very early, with physicians highly exposed to COVID-19-infected } \\
\text { patients receiving highest priority (December 2020-January 2021). Hospi- } \\
\text { tal started dispensing vaccine to patients in late December } 2020 \text { according } \\
\text { to priority based on patient risk factors for infection (January 2021-current) }\end{array}$ \\
\hline $\begin{array}{l}\text { Patients reluctant to present to Hospital with diseases or disorders } \\
\text { unrelated to COVID-19 infection }\end{array}$ & $\begin{array}{l}\text { Attributed to patient fear of contracting COVID-19 infection while in Hos- } \\
\text { pital (March 2020-current). Suspected cause of higher mortality of some } \\
\text { diseases unrelated to COVID-19 during pandemic (e.g., cardiovascular } \\
\text { diseases) }\end{array}$ \\
\hline
\end{tabular}

GI gastrointestinal

before the pandemic, residents, fellows, and attendings were prohibited from wearing scrubs outside the operating room, endoscopy suite, cardiac catheter suite, or interventional radiology suite.

Soon after pandemic onset, the hospital endoscopy suite transitioned from flimsy, single use, disposable surgical gowns to thick, impermeable, plastic gowns for endoscopy personnel that were laundered after each use to reduce transmission of COVID-19 in the endoscopy suite. Around April 1, 2021 the thick plastic gowns were replaced by flimsy, single-use, disposable endoscopy aprons or gowns that did not cover endoscopy personnel completely during endoscopies, apparently due to a shortage of the thicker, better, and more expensive gowns.

\section{Hospital Administration Requested All Full-Time Employed Beaumont Physicians to Voluntarily Defer or Relinquish Scheduled Vacations in April 2020. During late March 2020 Hospital administrators requested all full-time employed physicians to defer or relinquish vacations already scheduled}

for April 2020. In response, I voluntarily canceled a roundtrip flight and week-long vacation to Florida in early April 2020 which I had scheduled months earlier, despite my not having seen my wife for several months, needing a vacation after working intensely during the COVID-19 surge, and missing a planned celebration of the upcoming spring holidays with my family.

4. Enhanced Hospital Security. Before the pandemic, the Hospital during normal business hours had one hospitality clerk and no security guards manning major hospital entrances (except for the emergency room entrance which always maintained enhanced security), and had no hospital personnel guarding minor hospital entrances. With the pandemic onset, the Hospital initially closed the main (East) entrance; closed minor, unguarded, entrances; and maintained enhanced security, with 2 hospitality clerks and 4 other personnel, mostly previously furloughed rehabilitation technicians, manning major entrances from March-June 2020. All hospital employees, including GI employees, had 
to sign a form daily stating that they were healthy, without symptoms of COVID-19 infection, before gaining hospital entry for work. From March-July 2020 all patient visitors, whether visiting patients with COVID-19 infection or not, were barred entry to the hospital to reduce infection transmission. Enhanced security was gradually reduced starting August 2020, with security eventually reduced to 1 or 2 clerks at all 3 major entrances. Around February 2021 automatic doors were installed in the hallway connecting the Medical Office Building (which houses ambulatory clinics and private physician's offices) to the hospital. These automatic doors were mechanically opened by presenting hospital-issued security badges to an electronic sensor.

\section{Module Added on COVID-19 Infection for Mandatory} Annual Physician Education in 2021. As in prior years, the Hospital required all physicians to undergo lengthy annual mandatory education consisting of about forty modules and passing of exams required after each module to receive credit per module in both 2020 and 2021 despite the pandemic. The modules have always been virtual, by Internet, with presentation of slides or brief videos, and post-module multiple choice exams delivered by Internet. Modules in 2020 and 2021 did not require modifications for the pandemic.

In 2021 the Hospital introduced a mandatory educational module consisting of 12 slides on COVID-19 infection including symptoms and signs, prominent laboratory abnormalities, epidemiology, diagnostic testing, treatment, and vaccination. This module included only general medical knowledge on this subject.

\section{With the Pandemic Onset the Hospital Cafeteria Reversed} Course to Favor Plastic Disposable Utensils, Plastic Plates, and Plastic Food Boxes for Meals to Potentially Reduce COVID-19 Transmission Instead of Previously Favoring Recyclable Silverware and Plates to Support the Environ-

ment. The hospital eliminated the previous premium charge for using disposable (plastic) silverware, plates, and boxes with the pandemic.

The Hospital also installed plastic barriers, made of Lucite, in the Hospital cafeteria to separate food servers from customers. Also, Lucite barriers were erected between patients and hospital employees at numerous service spots in the Hospital such as Hospital cashiers, servers, and guides. Lucite barriers were also set up between individuals in conference rooms. These barriers were designed to reduce risks of transmitting COVID-19 infection.

7. Testing for COVID-19. Testing for COVID-19 became progressively more available, faster, and more accurate during the pandemic. Infectious disease physicians remarkably saw every suspected COVID-19 patient admitted to the Hospital and facilitated COVID-19 testing. The Hospital initiated a serological study on April 13, 2020, of many thousands of Hospital employees for COVID-19 infection (see V.1).

\section{Greater Availability of $\mathrm{N} 95$ and Other High Quality Surgical}

Masks. At the pandemic onset in March 2020, the Hospital, like other American hospitals, suffered from an acute shortage of surgical masks, especially N95 masks. At the time I had to beg to receive an N95 mask to see GI consults on patients with known COVID-19 infection (see Discussion), and had to reuse the same mask for an entire day before returning a mask to the hospital for re-sterilization and reuse. The situation rapidly improved with many more N95 masks becoming available, but physicians treating COVID-19 patients were still required to submit their old N95 masks daily for re-sterilization and reuse, through June 2020. Scarcity of N95 masks was alleviated by introducing the much cheaper KN95 masks, which became available for daily use without the need for re-sterilization and reuse. In July 2020, wearing face masks to cover the mouth and nose became mandatory while in the Hospital. About October 2020 hospital clerks began distributing complementary face masks at hospital entrances to hospital employees and visitors.

9. Vaccination Against COVID-19 Infection. The Hospital started offering employed house staff, including GI fellows, and all physician attendings, including GI attendings, vaccination against COVID-19 infection, using the Pfizer-BioNTech vaccine starting on December 13, 2020, with highest priority assigned to house staff heavily exposed to COVID19-infected patients, such as residents caring for ICU patients or working in medical wards with mostly COVID19-infected patients, and second priority assigned to other house staff, hospital-employed physicians, and physicians in private practice affiliated with the Hospital. The Hospital vaccines were administered for free as a public service.

I received an email to place myself on a waiting list for the Pfizer-BioNTech COVID-19 vaccine at 4:10 PM on December 21, 2020, and I immediately left the Hospital and traveled by car to the Beaumont Vaccination Center. Armed with this email, but without an appointment, I received my first vaccine shot at 4:45 PM after waiting only $15 \mathrm{~min}$ in line. I received my second Pfizer-BioNTech COVID-19 vaccine dose at the same vaccination site three weeks later. This vaccination center was highly efficiently run, with United States National Guardsmen and Beaumont Hospital security guards directing pedestrian traffic, and nurses administering the shots. All six GI fellows received their first vaccine dose by December 31,2020, soon after emergency approval of the vaccine from the FDA, and received their second dose by January 21, 2021. Prioritization of physician for vaccination appears justified because physicians voluntarily accepted extra risks of contracting COVID-19 infection by treating COVID-19-infected patients. 
In a third phase beginning late December 2020, the Hospital offered vaccination to patients $\geq 65$ years old, in a fourth phase offered vaccination to all patients $\geq 18$ years old in April 2021, and in a fifth phase offered vaccination to all patients $\geq 12$ years old in late May, 2021. The Hospital has vaccinated 170,000 patients with the first dose and 137,000 patients with the second dose by late April 2021 [26]. In late April 2021 the Hospital expanded to five vaccination sites, by establishing four walk-in vaccination clinics, which did not require patients to have scheduled appointments to receive the vaccine.

10. Reluctance of Patients to Present to Emergency Department (ED) or Be Admitted for Non-COVID-19-Related Disease. This phenomenon is attributed to patient fear of contracting COVID-19 during an emergency room visit or hospitalization. For example, during the pandemic in 2020 the rate of patients presenting and diagnosed with ischemic cardiac disease and hypertensive diseases significantly declined, whereas deaths from these diseases significantly increased in the USA likely due to patient inattention to cardiovascular symptoms [27, 28]. This may partly explain increases in annual mortality in America indirectly related to the pandemic.

\section{Physician Emotional Stresses (Table 5).}

\section{Six of Sixty ( $10 \%$ of) Medical Residents Working in the Hospital Contracted COVID-19 Infection During March-May}

2020, as detected prospectively by nasal swab testing of symptomatic individuals or retrospectively by subsequent serologic testing for antibodies against COVID-19 of asymptomatic individuals in a large serologic study initiated on April 13, 2020, by the Division of Infectious Diseases at the Hospital. Only half of COVID-19 seropositive medical residents experienced symptoms, and only one required hospitalization, which was brief and uncomplicated. These relatively benign infectious outcomes were attributed to the relative youthfulness of house staff. Combining the 36 GI attendings and 6 GI fellows, 5 of $42(12 \%)$ contracted COVID-19 infection during March-June 2020. Tragically, one house officer (an oral surgeon) died heroically in March 2020 from acute COVID-19 infection at another metropolitan Detroit hospital, while reportedly contracting the infection while triaging patients in the emergency room [29].

2. Ameliorating Emotional Stresses on GI Fellows. GI fellows experienced emotional stress from risks of contracting COVID-19 infection from infected patients in April and May 2020 while working as medical attendings on medical wards exclusively treating COVID-19-infected patients. As GI fellowship program director, I individually contacted all GI fellows twice weekly by telephone during April and May 2020 to discuss their emotional state and perceived workload burden to help support their morale and promote their emotional health. GI fellows, indeed, recommended one workload reduction to me that I implemented without

Table 5 Physician emotional stresses and stress reduction during the pandemic

\begin{tabular}{|c|c|}
\hline Factors contributing to physician stress & Changes (with time intervals) \\
\hline $\begin{array}{l}\text { Medical residents and fellows suffered higher rates of contracting } \\
\text { COVID-19 infection than general public }\end{array}$ & $\begin{array}{l}10 \% \text { of medical residents contracted COVID-19 infection (March-May } \\
\text { 2020). Generally had very mild disease manifestations due to relative } \\
\text { youthfulness of house staff }\end{array}$ \\
\hline Actions to ameliorate stress of GI fellows & $\begin{array}{l}\text { Program Director (me) contacted all GI fellows twice weekly during } \\
\text { change of GI fellows' schedule to become medical attendings during } \\
\text { pandemic surge (April-May 2020) }\end{array}$ \\
\hline $\begin{array}{l}\text { Actions to reduce paperwork of key faculty to evaluate GI fellows } \\
\text { during surge }\end{array}$ & $\begin{array}{l}\text { Monthly evaluation forms of GI fellows greatly abbreviated and key } \\
\text { faculty meeting to review GI fellows performance canceled due to } \\
\text { pandemic (March-May 2020) }\end{array}$ \\
\hline $\begin{array}{l}\text { Annual GI fellow evaluations by ACGME and by National Board of } \\
\text { Medical Examiners }\end{array}$ & $\begin{array}{l}\text { Maintained fully and on time despite pandemic to not delay annual GI } \\
\text { fellow promotions or graduations (June 2020) }\end{array}$ \\
\hline Complaints against GI fellows & $\begin{array}{l}\text { Tenfold higher rate during first } 20 \text { days of pandemic, but then rapidly } \\
\text { decreased to baseline rate (March-April 2020) }\end{array}$ \\
\hline Annual party for graduating GI fellows & $\begin{array}{l}\text { Held virtually by teleconference, with dinners sent to graduating fellows } \\
\text { delivered from a restaurant (June 2020). Annual graduation party } \\
\text { scheduled for June } 2021 \text { at a local restaurant (June 2021) }\end{array}$ \\
\hline Annual GI division holiday party & $\begin{array}{l}\text { Holiday party did not officially occur, but was replaced by a small meet- } \\
\text { ing of faculty and GI fellows (December 2020) }\end{array}$ \\
\hline $\begin{array}{l}\text { Annual medical school parties and ceremony for graduating medical } \\
\text { students }\end{array}$ & Parties held virtually (May 2020-May 2021) \\
\hline
\end{tabular}

GI - gastrointestinal, ACGME_-Accreditation Council for Graduate Medical Education 
adversely affecting patient care: the originally planned work schedule for April-May 2020 of 2 GI fellows on-call each weeknight to cover separately the exclusively COVID-19 medical wards and the emergency GI consult service was changed to have only one GI fellow on-call on weeknights to cover both services simultaneously. Starting June 1, 2020, my intense engagement with GI fellows as program director reverted back to baseline as the work rotations for GI fellows returned to baseline (without fellows supervising as general medical attendings on exclusively COVID-19 wards).

\section{Stress on Full-Time GI Attendings from Completing} Detailed Mandatory Monthly GI Fellow Evaluations Reduced by Temporarily Shortening Fellow Evaluation Forms. Supervisory GI attendings normally evaluate GI fellows monthly using a somewhat lengthy, comprehensive, computerized questionnaire involving 7 medical competencies plus an overall performance evaluation. GI clinical faculty failed to perform these evaluations in a timely manner from MarchMay 2020 because they were overwhelmed by clinical work from the pandemic. During the surge, the GI fellowship program director (me) replaced these time-consuming monthly GI attending evaluation forms with highly abbreviated forms asking only 2 questions that required only yes or no answers and took only one moment to complete per evaluation. GI attendings successfully completed these abbreviated evaluation forms and sent them to the program director (me) in a timely manner. Abbreviated monthly evaluation forms were replaced by the traditional, somewhat lengthy, monthly evaluation forms starting June 1, 2020.

Normally the 6 key GI faculty meet quarterly to review clinical and academic progress of the 6 GI fellows, but the April 2020 quarterly meeting was canceled and replaced by two brief questions (requiring yes or no answers) sent by email by me to all 6 key GI faculty regarding significant problems with each fellow and whether each fellow had satisfactorily progressed toward promotion/graduation during the prior quarter. This short evaluation was performed exigently at the height of the pandemic surge. Key faculty resumed regularly scheduled quarterly meetings to evaluate GI fellows in June 2020.

Annual evaluation forms for all 6 GI fellows by the ACGME and the National Board of Medical Examiners were completed on time in June 2020 to enable third year GI fellow to graduate and become eligible to sit for the GI boards and to permit first- and second-year GI fellows to be promoted on time to the next year of fellowship. These forms were not modified, abbreviated, or delayed due to the pandemic because completed forms were required for GI fellow promotion or graduation on time.

4. Complaints Against GI Fellows for Postponing Elective GI Endoscopies or for Deferring Physical Examinations in
Patients with COVID-19 Infection. To reduce work-related stress on endoscopy staff during the COVID-19 surge, inpatient endoscopies for elective indications were postponed for at least several weeks to be performed as outpatients. This quickly caused several complaints about GI fellows deferring elective inpatient endoscopies. Medical attendings and house staff also complained against GI fellows providing delayed or inadequate GI consultations on COVID-19-infected patients. These complaints against GI fellows abruptly became an acute problem, with a tenfold increase in the rate of complaints to four 4 complaints lodged in the first twenty days of the pandemic compared to the baseline rate of about 5 complaints annually before the pandemic! Moreover, complaints during the early pandemic were addressed outside the GI division (to the Chair of Medicine or Hospital administrators of GME) rather than within the GI division to the chief of GI or GI fellowship program director, as previously often occurred. I advised GI fellows and GI attendings to proactively engage medical house staff and attendings when postponing GI endoscopies in patients with COVID-19 infection to prevent such complaints. This problem rapidly abated; the high rate of complains during the first 20 days of the pandemic crisis reverted back to the baseline rate of about 5 complaints annually, thereafter.

\section{Annual Graduation Party for GI Fellows Celebrated Virtu-} ally in June 2020. Every year the Division traditionally celebrates a graduation party to honor graduating GI fellows. The fellows and their spouses (or significant others) are invited to the party as well as GI physician assistants, secretaries, program coordinator/manager, fellowship program director, Chief of GI, and voluntary and full-time GI attendings. For 2006-2019 the graduation party was always held at a local restaurant and the costs of the party were subsidized by an academic fund donated by a philanthropist to the Division. In June 2020, the party was held virtually rather than physically at a restaurant. To simulate the traditional party experience, each graduating fellow ordered two fully catered takeout dinners which were delivered to their home from a local restaurant of their choice, and which were paid for by the Division. The event was held remotely with partygoers connected by telephone conference call. GI fellows, including the graduating GI fellows, and key GI faculty spoke at the virtual party by telephone conference call. While everybody appreciated this virtual party, especially the graduating GI fellows, it lacked the camaraderie and spontaneity of "live" graduation parties. The two graduating GI fellows were awarded their diplomas and given gifts by GI faculty on the day after the virtual party.

6. Other Annual GI Divisional Parties. For the prior 15 years, the division celebrated a holiday party around the Christmas and New Year holidays that was held at a local restaurant, 
with the party funded by the Division. In December 2020, the party did not officially occur, but several attendings met informally with GI fellows to celebrate the holidays. The hospital traditionally celebrates a hospital-wide graduation party and awards ceremony every June for all graduating residents and fellows in all divisions and departments. This celebration was canceled in June 2020 because of the pandemic.

\section{Medical School Annual Parties and Graduation Convoca-} tion. The medical school traditionally celebrates the following events annually: a white coat party for medical students entering the clinical wards, a party on match day when fourth-year medical students are notified of their match with residency programs, and a graduation party and convocation in which graduating medical students receive their diplomas and in which deserving medical students and faculty receive awards. All these celebrations were changed from physical to virtual in 2020 .

\section{Graduate Medical Education (Table 6).}

\section{Changes in Hospital GME Department, and Change in Fellowship Program Managers Work Schedules. During the pandemic the Hospital GME department was actively involved in managing work schedules of house staff, includ- ing GI fellows. Committee meetings of GME administra- tors with program directors and representative house officers were changed from monthly to weekly during April-June 2020 to accomplish timely changes in residency and fellow- ship programs in response to the pandemic. Meetings were changed from physical to virtual to reduce risks of transmit- ting COVID-19 infection.}

Table 6 Graduate medical education, gastrointestinal research, and gastrointestinal and hepatology professional societies

Hospital GME and GI professional societies

Hospital GME Committee

Program managers, including GI program manager

Annual hospital-wide medical education week

Annual in-service examinations of GI fellows, administered by the American Gastroenterology Association

Annual GI fellowship program survey by ACGME-RRC

ACGME-RRC institutional site visits

Annual collection of physician scholarly publications and other academic achievements at Hospital for publication in a Hospital-wide publication

Gastroenterology research

Research on COVID-19 infection

National/international GI and hepatology professional societies
Changes (with time intervals)

Met virtually instead of physically during pandemic. Also met more frequently (once weekly) instead of once monthly during pandemic to promptly effect changes in policy due to the pandemic (April-June 2020)

Furloughed (March-May 2020). Program managers instructed to work virtually from home to reduce risks of contracting COVID-19-infection (June 2020-current)

Previously held physically in classrooms with medical residents and fellows presenting their research physically in classrooms and several lectures presented physically by a visiting professor. Almost entirely canceled (May 2020) due to pandemic with only virtual presentations of research projects and no lectures by a visiting professor. Held virtually to reduce risks of pandemic (May 2021)

Held annually using remote proctoring of computerized examinations (March 2020 and March 2021)

Annual surveys of GI fellows and of key GI faculty emailed March 2020. Both surveys canceled (April 2020). Annual surveys for 2021 emailed (March 2021) and completed and returned (April 2021) despite pandemic since physicians surveyed virtually by email

Physical site visits canceled due to pandemic (March-July 2020). Restarted site visits virtually (Summer 2020-current). Site visit of Beaumont GI fellowship program postponed with physical site visit unlikely before 2022

Publication of 2019 scholarly achievements delayed (December 2020). Publication of 2020 scholarly achievements set to be published almost on time (expected June 2020)

Less GI research electives during fellowship due to pandemic (MarchJune 2020)

Recommended by this author due to timeliness and potential clinical impact. Accelerated peer-review of papers on COVID-19 infection (March 2020-current)

Changed scheduled conventions from physical to virtual delivered by Internet (March 2020-current)

GME graduate medical education, GI gastrointestinal, ACGME Accreditation Council for Graduate Medical Education, RRC residency review commission 
All program coordinators/managers, including the GI fellowship program manager, were instructed to work from home starting June 2020-current due to the pandemic to decrease exposure to COVID-19 infection, and to perform their duties by telephone or Internet. This policy change mildly decreased the program manager's efficiency, which was mitigated by program managers coming to the hospital for important meetings.

2. Changes in Annual Education Week. This academic Hospital, in collaboration with the medical school, holds an education week in May annually to recognize house officers who present posters or brief podium talks based on their clinical research projects to compete for prizes based on the clinical importance and quality of their research. The education week also features a nationally known visiting professor who presents several lectures in academic medicine, which are endowed by a grant from a philanthropist. Annual education week meetings were always held live in conference rooms or assembly halls before the pandemic. The annual education week was extremely limited in 2020 due to the pandemic, with only research posters presented virtually by Internet and podium talks and lectures by a visiting professor canceled. The education week was, however, reinstituted in May 2021, including awarding prizes for best research papers authored by residents and fellows. Research abstracts were only presented virtually with no podium or other physical research talks, but lectures by an invited visiting professor were presented live physically in an auditorium and streamed live virtually by Internet.

3. Annual In-Service Examination for GI Fellows. The annual in-service exam for GI fellows evaluates their cognitive skills in GI and hepatology via a 3-h-long examination involving multiple choice questions in the fields of hepatology, esophagus, stomach, small bowel, colon, hepatobiliary tree, pancreas, and GI endoscopy. The grades of individual GI fellows are compared to that of their peers, stratified according to GI fellowship year. This test, administered by the AGA, was held without postponement in March 2020 and March 2021. It was held virtually by Internet, as in previous years, without any changes required because of the pandemic. This annual examination provides GI fellows a valuable service by indicating how they compare with their peers at the same year of GI fellowship in each individual test section to identify topics in which they are comparatively weak and may want to study further to prepare for Board examination.

\section{Annual Program Surveys by ACGME and Residency Review} Commission (RRC). The ACGME and RRC normally comprehensively survey annually by Internet all 6 GI fellows with about 30 questions about the academic and clinical quality of the fellowship program and all 6 key GI faculty at the Hospital with about 30 similar questions to indicate the clinical and teaching quality of the program. Both sets of questions are detailed and relatively time-consuming. These surveys are normally mandatory. These surveys were issued in March 2020 as mandatory, with a required return in April 2020. However, both surveys were abruptly canceled after being issued due to the pandemic, and were subsequently reinstituted on a voluntary basis in May-June 2020. Mandatory annual surveys resumed in the 2020-2021 academic year. Surveys were issued to both GI fellows and key GI faculty at the Hospital in February 2021, to be returned in March 2021. The resulting GI fellow and key GI attending evaluations were sent to program directors, together with extensive descriptive statistics comparing institutional performance with nationwide performance in late April 2021. Descriptive evaluation statistics were sent anonymously, without identifying individual evaluators by name.

5. ACGME and RRC Site Visits. The ACGME and RRC periodically perform site visits of accredited residency and fellowship programs, with site visit interval set according to program performance during the prior site visit. Site visits are generally prolonged affairs requiring one or two RRC surveyors to carefully survey Hospital fellowship and residency programs. For example, two site visitors spent one week surveying the Department of Medicine at the Hospital in the last site visit. During the site visit, surveyors meet program directors, division chiefs, program managers, hospital administrators, medical residents and fellows, and the designated official of the hospital-wide GME department. Surveyors audit divisions and departments to check that all required paperwork by fellowship and residency program directors and program managers is complete, accurate, and up-to-date. Surveyors report their findings on quality of residency and fellowship programs to the RRC which then votes, depending upon the surveyors' findings, whether to grant programs continuing accreditation; sets the length of time for continuing accreditation; decides whether to impose citations or warnings that must be addressed by the institution, residency, or fellowship programs in a timely manner; and determines whether to place a program on probation or suspension. The ACGME suspended all site visits for residency and fellowship programs during the surge in March-June 2020 and then resumed site visits in the summer of 2020, while changing the survey format from physical to virtual site visits. Paperwork previously checked during the physical site visit is now submitted by Internet. For example, the Division of Critical Care and Pulmonary Medicine training program at the Hospital has been scheduled for a virtual rather than physical site visit in October 2021. The ACGME initially planned a site visit for the Internal Medicine and GI fellowship program at the Hospital in 2020, but this was canceled because of the pandemic and now is deferred until 
at least 2022 or likely longer, because the pandemic delayed the entire ACGME working schedule.

It is unknown whether replacement by the RRC of onsite visits by virtual visits will be temporary or permanent. Physical site visits involve large expenditures by the RRC because site surveyors visit a hospital typically for about one week, incurring costs of airline flights, local hotel stays, and other travel expenses, while virtual visits do not involve such expenses. Virtual visits, however, do not provide the camaraderie and intimate informal conversations available at physical meetings.

\section{Annual Collection of Physician Scholarship Produced at} All Beaumont Network Hospitals During 2019 Calendar Year Delayed from March to December 2020 Due to Pandemic.

The annual Hospital collection includes a comprehensive list of scholarly activities, including publications (original articles, reviews, case reports, and etc.) published in peerreviewed journals, chapters in books, abstracts presented orally or as posters at national (international) professional conventions presentations, and invited talks at academic hospitals during the prior year for all residents, fellows, clinical attendings, and research faculty in all Divisions and Departments at all Beaumont Network Hospitals. This collection is published annually as a list of scholarly activities, comprising about 200 pages, normally published in May or June of the year after which the scholarly activities occurred. Publication in 2020 of scholarly activities for 2019 was delayed until December because of the pandemic. Scholarly activities for 2020 were collected much earlier, in April 2021, and should be published much earlier in June 2020 because of the declining pandemic impact.

\section{GI Research and Professional Societies (Table 6).}

1. Gastroenterology Research. The pandemic may lead to less resident and fellow research electives and less time dedicated to clinical research because of a greater clinical load. However, research on COVID-19 infection has blossomed. The pandemic provides physicians a-once-in-a-lifetime opportunity to perform exciting, cutting-edge, research on COVID-19 that can potentially save patient lives. Despite my clinical obligations and emotional stress from the pandemic, I redoubled my efforts to report on COVID-19-related clinical entities and have already published with coauthors 4 studies, including three case reports and one letter to the editor on the pandemic [16,30-32], not including this presently submitted paper. I encourage other researchers to consider focusing their research on COVID-19 infection.

\section{Accelerated Peer-Review and Decisions on Submitted Clinical Papers on COVID-19 Infection. In my experience,}

decisions on publication of papers submitted for peer review normally take about two months or longer. However, I had a case report on a COVID-19-infected patient accepted within one week of submission and preliminarily published one week later in a leading clinical GI journal [30]! Accelerated peer-review in major medical journals, including leading GI journals, is justified by the overwhelming clinical need to disseminate new medical findings to potentially save lives of COVID-19-infected patients [33].

3. National/International GI Professional Conventions Changed from Physical to Virtual in 2020. The major annual professional national/international conventions in 2020 were all scheduled as physical events in specific cities, including Digestive Disease Week sponsored by the American Gastroenterology Association and American Society for Gastrointestinal Endoscopy scheduled for May 2020 in Chicago, Illinois; American College of Gastroenterology scheduled for October 2020 in Memphis, Tennessee; and American Association for the Study of Liver Diseases scheduled for November 2020 in Boston, Massachusetts. These conventions are generally massive, sometimes exceeding 10,000 conventioneers and involving hundreds of commercial exhibitors. These conventions were, however, changed to virtual meetings, conducted via the Internet, to reduce transmission of COVID-19 infection in crowded convention halls. This change saved conventioneers time and money by not having to fly round-trip to the host city and by not having to stay at local convention hotels. The author, however, feels significant loss from not having physical meetings due to loss of professional camaraderie and interactions between speakers, researchers, exhibitors, and physicians. The Digestive Week Convention in May 2021 was also held as virtual rather than physical [34]. Many physicians look forward to resuming physical meetings with colleagues and friends from other cities throughout the country, hopefully, in the near future.

\section{Discussion}

This work demonstrates how one extremely large, academic, GI division, in an academic tertiary care hospital that is the primary teaching hospital of a medical school, reorganized when facing massive clinical needs caused by an explosive pandemic from zero patients to $>$ one-fourth of all hospital patients within one month, for a total onslaught of $>13,000$ infected patients during one year. The suddenness of the crisis is partly due to Detroit being a local early pandemic epicenter, like New York City, and the Hospital serving as a tertiary referral center for COVID-19-infected patients. This Hospital is an unusual academic hospital in that most attendings are voluntary in private practice, with $36 \mathrm{GI}$ attendings 
in private practice and only three hospital-employed GI attendings, like Baylor Medical Center, an academic hospital with a similar attending composition. GI practitioners in private practice had to agree to Hospital practice changes made during the pandemic. This involved complicated negotiations between the GI division and GI attendings, such as assigning voluntary GI attendings for GI endoscopies on staff (ward) patients with COVID-19 infection.

The medical school made minor errors in rapidly implementing revolutionary changes in clinical policies and practices, but it should not be judged too harshly, but rather praised, for quickly performing mostly appropriate corrections in a very challenging, rapidly changing, unprecedented, medical crisis. The medical school acted early, quickly, and decisively to manage the crisis. It abruptly shut down, only to reopen four days later after intensive discussions and decisions about the raging crisis. It sought advice and council with medical school administrators, administrators at other medical schools, Beaumont Hospital administrators, basic and clinical faculty, and medical students on medical school reorganization [10]. The medical school established ethical and rational goals to: (1) protect the end users, namely medical students, as well as faculty and other employees from contracting infection; (2) avoid delaying medical school graduation for one year due to the pandemic, following the motto the "show must go on"; and (3) restructuring preclinical and clinical education to prevent pandemic health repercussions while minimizing medical school changes [10].

Traditional "live" lectures were replaced by virtual lectures. The medical school first used "canned" lectures of audiovisual tapes which had been filmed "live" during the previous academic year. This policy had advantages in that it could be implemented quickly and without costs, but faced mild drawbacks including: (1) not incorporating into preexisting audiovisual tapes curriculum changes recommended during the ensuing year; (2) several lecturers dropped from the lecture roster due to questionable teaching ability were perforce still delivering "canned" lectures; and (3) questions asked during prior year lectures could not be easily edited out from "canned" lectures. To minimize these drawbacks, medical school administrators several months later authorized a new set of taped audiovisual "virtual" lectures, presented by the newly scheduled lecturers. This new set of lectures, however, created new problems: (1) the medical school had a shortage of IT personnel to assist lecturers in taping their lectures using computer technology because one-fifth of IT employees had been furloughed in March-April 2020 due to budget deficits; this led to educators not trained in IT supervising audiovisual taping of lectures; several lectures were lost per course because of technical mishaps; (2) in implementing "virtual" lectures, the medical school sequentially used two commercial computer interfaces both of which proved too complicated and unsatisfactory for use and were successfully replaced by Microsoft Teams which eventually functioned nearly flawlessly; and (3) several "live" virtual lectures had to be canceled due to computer malfunctions in early Spring 2020.

The Hospital, likewise, made minor errors in rapidly implementing revolutionary changes in clinical policies and practices, but it should not be judged too harshly for quickly performing mostly appropriate corrections in a very challenging, rapidly changing, unprecedented, medical crisis. A potential criticism of the hospital's actions may be that it acted using an opaque decision process that did not involve staff physicians. Physicians and nurses deserve immense credit for heroically managing the crisis professionally, by willingly undertaking health risks as part of their job, without receiving extra compensation. Minor errors are obvious retrospectively, but not necessarily appreciated prospectively. For example, Dr. Anthony Fauci, an internationally acclaimed virologist, made a blunder early in the pandemic by advising the public not to wear facemasks [35].

The Hospital conserved its clinical workforce, and financial resources by temporarily closing parts of the Medical School in which the Hospital is an equal partner of Oakland University. The 30 live course lectures in second-year GI and hepatology course were modified by audiovisual taping these lectures and transmission by Internet. The pandemic severely reduced clinical revenue for Detroit metropolitan hospitals, including the Hospital and GI division, but this deficit was substantially reduced by federal governmental support. Beyond the change from physical to virtual lectures, the medical school and Hospital changed numerous other educational and clinical activities from physical to virtual, including: GI divisional conferences, annual education week lectures, committee meetings, GI fellowship applicant interviews, program manager communications with program directors, and divisional parties or graduation ceremonies. ACGME site visits and national GI conventions were also changed from physical to virtual.

Virtual activities save time and money because of easy access to meetings without travel time and expenses and reduce risk of infection transmission at such meetings, but virtual activities lack spontaneity, camaraderie, and personal interactions between speakers and live audiences due to computerized communications. Can the watching of a sport event at home on television compare to the excitement and intense emotions of watching the same event "live" and in person at a stadium? For example, when I delivered a virtual lecture by videoconference to medical residents in June 2020, I felt emotionally detached by lack of visual feedback from my virtual audience while lecturing. I had to walk $5 \mathrm{~min}$ to the audiovisual center and wait ten minutes for an IT technologist to set up my virtual talk. Lecturers presenting virtually cannot gauge audience reactions. Other 
lecturers expressed similar feelings. Audience attentiveness and satisfaction may decrease during virtual lectures.

GI attendings in private practice may prefer virtual instead of physical lectures because virtual lectures avoid travel time and can be taped at a convenient time for subsequent presentation weeks later instead of being delivered live at a specific time during a day in which the private GI practitioner usually sees patients.

Videoconferencing created a need for more information technologists and upgrading computer equipment for videoconferencing. Information technologists should be readily available to help clinicians set-up videoconferences because clinicians typically lack sophistication in computer technology. During the early change to videoconferencing, few hospital computers had cameras or software for transmitting videoconferences. My ancient hospital computer installed about ten years before the pandemic had to be upgraded to a new computer provisioned with a video camera and microphone to enable videoconferencing during the pandemic. Some conferences early during the pandemic before the computer upgrades were conducted via cell phone conference calls.

The division changed all GI clinic visits to virtual during the pandemic peak from March-June 2020 before modifying this change to about half of clinic visits being virtual and half being physical from July 2020-current. GI clinic visits were reduced by $50 \%$ of the pre-pandemic rate by Hospital administration during the pandemic peak to prioritize care for COVID-19-infected patients. GI fellows currently see about the same number of patients as they saw before the pandemic: about 9 patients are scheduled per GI fellow and about 6 patients are seen because of no shows but about half of the clinic visits are virtual (televisits).

The Hospital strongly recommended change in-hospital consults of COVID-19-infected patients from physical to virtual to decrease transmission of the infection to physicians during the pandemic from March 2020-current. Patients without COVID-19 infection are seen by traditional physical visits. These twin changes received the imprimatur of the Centers for Medicare and Medicaid Services which approved insurance reimbursement for virtual patient visits [11].

Virtual instead of physical activities will likely become the standard in many situations due to lower costs and eliminating travel time, but the benefits of physical activities must be considered in the equation. Virtual meetings are not allor-none and can include physical attendance for participants who can easily attend physical meetings (e.g., located nearby) and virtual attendance for far away participants. A two-tiered system may emerge: virtual for low priority activities and physical for high priority activities. For example, GI clinic visits may be physical for sick patients and virtual for relatively stable patients. Physical visits have the advantage of physical examination which can be important in patient evaluation. Before the pandemic, GI clinic televisits were not performed and not billed because Medicare and Medicaid only instituted reimbursement for televisits during the pandemic [11]. The closest activity resembling televisits before the pandemic was telephone calls from physicians to patients or vice versa, for which I did not bill for.

Simulators to train GI fellows in GI endoscopy is in its infancy. The Hospital has a computerized simulator laboratory which is primarily used to train surgeons in sophisticated technologies, such as robotic surgery, but also has a simulator endoscope that simulates esophagogastroduodenoscopy, colonoscopy, or ERCP. Such simulated endoscopes are somewhat helpful for very early endoscopic training of GI fellows, but are rather unsophisticated, only roughly approximate the real life situation of endoscopy in a live patient, and offer insufficient verisimilitude to help train even mildly experienced GI fellows. The current generation of simulated endoscopes needs to improve with more sophisticated computer technology, better simulated optics, and improved mechanical construction to genuinely help train GI fellows. The pandemic demonstrated a need to teach GI fellows endoscopic techniques without involving patients due to endoscopic risks in performing endoscopy on COVID19-infected patients. As program director, I conducted three one hour teaching sessions with the first-year GI fellows in July 2020 using the endoscopic simulator, but these fellows quickly "graduated" to perform real endoscopies on real patients.

GI staff consults were mildly decreased in number during the pandemic to about seven per day from a pre-pandemic average baseline of eleven per day because of a reduced hospital daily census during the pandemic peak (perhaps because patients feared contracting COVID-19 infection inhospital). The volume of Hospital inpatient GI endoscopies is extremely depressed to about 50 per day in May 2021 (half of pre-pandemic baseline) because patients and physicians often defer elective in-hospital endoscopies to the outpatient setting; barriers for scheduling inpatient endoscopies due to shortages of anesthesiologists, nurse anesthetists, and endoscopy nurses; and increased turnaround times for cleaning endoscopic rooms between cases. These factors could potentially retard the progression of first-year GI fellows to achieve endoscopic proficiency.

GI clinic visits for patients were typically deferred for 6-8 weeks during the pandemic peak. This lag reached a steady state and has not caused a large backlog for GI clinic visits. However, GI clinic patients face a long backlog for endoscopy of at least several months due to longer allotted endoscopy time slots because of increased cleaning times between cases and a current shortage of anesthesiologists, nurse-anesthetists, and endoscopy nurses. The Hospital 
has attempted to address the endoscopy backlog by sending some patients to a satellite ambulatory endoscopy unit located several miles away from the hospital with partial success.

GI electives for medical students and residents were canceled during the pandemic peak but were subsequently restored. Residents and medical students can benefit the GI clinical service. Their service was sorely missed by the GI service during the pandemic peak. Residents can see GI consults when GI fellows are performing endoscopies and enable the GI service to keep up with the daily rush of GI consults. Experienced residents can particularly help by initially seeing emergency GI consults, such as GI bleeders, when the GI fellow is busy performing GI endoscopies. Medical students and residents are critical components of a teaching GI team, enabling GI attendings to teach and lecture on clinical topics related to patients seen on teaching rounds. The presence of medical students and residents change service rounds to teaching rounds. Residents and medical students benefit from intense exposure to GI pathology, GI diseases, and GI endoscopy during the GI monthly rotation. They can observe GI attendings at work to determine whether they are interested in pursuing a professional career in GI, are exposed to GI attendings as potential mentors for research projects, and meet GI attendings who can write letters of recommendation on their behalf. Medical residents resumed taking GI electives in July 2020 and medical students resumed taking GI electives in March 2021 as the pandemic has abated. These rotations are essential for the institution to train future practicing doctors in GI patient care.

This work has limitations. First, this work was written by one investigator. The investigator, however, claims expertise from a long history in hospital administration and medical school education as described in the Methods section. The author was prospectively, actively involved in the reorganization. Single authorship might potentially introduce observer bias, but the author focused on objective data. The author did not withhold errors committed by the institutions. These errors were minor and transient. Review of these errors is potentially instructive to prevent recurrence. Second, this review might be criticized for reporting details outside the GI division or medical school in a clinical GI journal. However, actions outside the GI division contributed greatly to the hospital atmosphere and work environment of GI attendings, and GI fellows, and to the clinical experiences of hospitalized patients. This report included all changes that I felt affected my clinical practice, my work as an employee, and my emotional state, as well as affecting other divisional employees, medical students, or patients. For example, enhanced hospital security, might be considered irrelevant to academic GI departmental reorganization, but is relevant to increasing anxiety of GI faculty, house staff, and their patients. Many important details external to the division are previously unreported. Third, this paper may be criticized for lengthiness, but an unprecedented, reorganization of the GI division and affiliated institutions by a historic pandemic merits comprehensive reporting. The length of this paper reflects its thorough research and comprehensive reporting.

I remember and will never forget my first forceful confrontation with the explosive pandemic surge upon entering the hospital observation unit in the windowless hospital basement at high noon, circa March 13, 2020. In these cavernous hallways, I reconnoitered with three fellow soldiers, a medical attending in the observation unit, the physician's assistant assigned to working with me, and an EKG technician. The lurking insidious enemy was present but invisible and could shoot to kill from any perch if we got too close - less than six feet away. We palpated the risks in manning the trenches, just like in the Great World War (also known as the War to End all Wars or World War I). Among the four of us, only the physician's assistant working with me was wearing a facemask. We were as edgy as the untried soldier in the Red Badge of Courage. We lacked effective tools, guidance, and marching orders. The EKG technician complained that she had already entered dozens of patient rooms that day to perform EKGs without facemask protection. The attending worried about his risks in seeing new patients with unknown COVID-19 status. The physician's assistant told me to get a facemask forthwith. I hunted for twenty minutes for a facemask, and found the only remaining N95 facemask, after searching six supply rooms, before I saw my consults, several of whom proved to have COVID-19 infection. There is true grit in a grunt just following orders on fateful days.

Despite the grim situation, Beaumont healthcare workers who risked their lives and health to treat COVID-19-infected patients received extraordinary public support and praise as expressed by emails posted by charitable organizations, grateful patients, and ordinary citizens; by posters cropping up on Hospital grounds stating "Beaumont healthcare workers are our heroes"; and by at least one giant billboard erected just 1 block from the hospital stating, "THANK YOU! Health Care Heroes-Beaumont." On Friday April 17,2020 , a procession of $>100$ police cars, fire trucks, and ambulances, with several hundred participants in the vehicles circled Beaumont Hospital to honor healthcare professionals working at Beaumont Hospital, Royal Oak who risked their lives by taking care of patients with COVID-19 infection (Fig. 1). An extremely large rescue helicopter was flying overhead to lead the procession. The procession had just come from the main Henry Ford Hospital.

As I left the hospital on Sunday at twilight in April 2020, after working all day on this paper, I was surprisingly greeted by about 40 "civilian" drivers in parked cars bonking their horns in unison and twinkling their blinker lights, with their car passengers excitedly pumping up and down hand-made signs in synchrony chanting "Beaumont doctors 


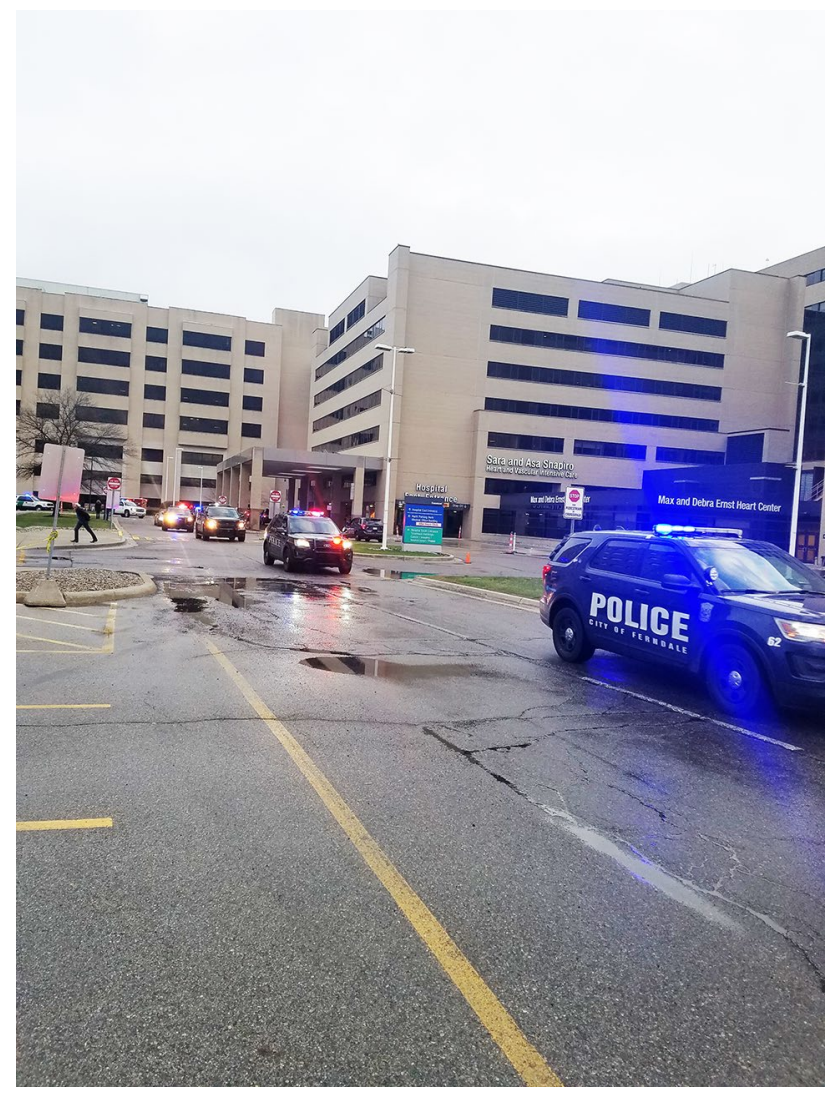

Fig. 1 Photograph of part of an extraordinary procession of more than one hundred vehicles, including police cars, fire trucks, and ambulances, driving slowly around Beaumont Hospital, after visiting Henry Ford Hospital Center and other Detroit-area hospitals, with their emergency lights blinking and sirens blaring to salute the healthcare professionals risking their lives in treating patients with COVID19 infection at Beaumont Hospital, Royal Oak. One very large medical rescue helicopter hovering above the procession is not shown. Photographed at 7:00 PM on April 17, 2020

are our heroes" and "Beaumont nurses are the greatest." As I slowly drove from the parking lot weary after a long day, I bonked my horn, turned on the blinker lights of my car, and gave a thumbs up sign in unison with these supporters who responded by loudly cheering, noisily bonking their horns, and rhythmically pumping up and down their hand held signs in support. I took this as a sign that humanity, teamwork, and unity will get us through this awful mess. One week later, I heard four triumphant musical refrains over the hospital loudspeaker system during $15 \mathrm{~min}$, each of which signaled successfully weaning one COVID-19-infected patient off mechanically assisted ventilation. Perhaps we are turning the corner in the Hospital, greater Detroit, Michigan, and America.

Postscript: After May 2020 when this paper was first submitted, some emergency measures were reversed or modified at Beaumont Hospital as the surge receded, reflecting decreasing numbers of patients hospitalized with COVID-19 infection but many other restrictions were maintained. Another pandemic wave hit the Hospital in April 2021.

At the suggestion of the editorial board of Digestive Diseases and Sciences, I extensively revised this paper to include not only initial changes during the pandemic peak in March-May 2020, but to incorporate subsequent changes through May 2021. This work prospectively follows the Hospital reorganization necessitated by the pandemic.

Author's contributions Cappell, MS initiated this article and wrote the entire manuscript.

Funding None.

\section{Declarations}

Conflict of interest The author declares no conflict of interest. In particular, Dr. Cappell, as a member of the United States Food and Drug Administration (FDA) Advisory Committee for Gastrointestinal Drugs, 2013-2018, affirms that this paper does not discuss any proprietary, confidential, pharmaceutical data submitted to the FDA and reviewed by Dr. Cappell. Dr. Cappell was $>2$ years ago a member of the speaker's bureau for AstraZeneca and Daiichi Sankyo, co-marketers of Movantik. Dr. Cappell had one-time consultancies for Mallinckrodt and Shire $>2$ years ago. This work does not discuss any drug manufactured or marketed by AstraZeneca, Daiichi Sankyo, Shire, or Mallinckrodt.

IRB approval Beaumont Health System exempted/approved this study on $4 / 14 / 2020$

\section{References}

1. WXYZ (ABC Television News). First cases of coronavirus confirmed in Michigan. One each in Oakland and Wayne counties. Available at: www.web.archive.org/web/20200311025008/https:// www.wxyz.com/news/coronavirus/first-cases-of-coronavirusconfirmed-in-michigan-one-each-in-oakland-and-wayne-count ies. Accessed April 14, 2020.

2. Smith M, Mervosh S. Michigan's Covid wards are filling up with younger patients. New York Time April 25, 2021. Available at: https://www.nytimes.com/2021/04/25/us/michigan-covid-young er-people-hospitalized.html.

3. Gross SA, Robbins DH, Greenwald DA, Schnoll-Sussman FH, Pochapin, MB. Preparation in the Big Apple: New York City, A new epicenter of the COVID-19 pandemic. Am J Gastroenterol. 2020 Jun;115:801-804. https://doi.org/10.14309/ajg.0000000000 000636. Am J Gastroenterol. 2020. PMID: 32427684. Accessed May 4, 2021

4. Papaefthymiou A, Koffas A, Kountouras J, Doulberis M, Kaltsa A, Tsiopoulos F, et al. The impact of COVID-19 pandemic on gastrointestinal diseases: a single-center cross-sectional study in central Greece. Ann Gastroenterol. 2021;34:323-330. https://doi. org/10.20524/aog.2021.0600. Epub 2021 Feb 26.Ann Gastroenterol. 2021. PMID: 33948056.

5. Koo CS, Siah KTH, Koh CJ. Endoscopy training in COVID-19: Challenges and hope for a better age. J Gastroenterol Hepatol. 
2021 Apr 19. https://doi.org/10.1111/jgh.15524. Online ahead of print. J Gastroenterol Hepatol. 2021. PMID: 33871079

6. Li J, Li C, Wang X, Wang Y, Zhou Y. Considerations and perspectives on digestive diseases during the COVID-19 pandemic: a narrative review. Ann Palliat Med. 2021 Apr;10:4858-4867. DOI: https://doi.org/10.21037/apm-20-2124. Epub 2021 Apr 1.Ann Palliat Med. 2021. PMID: 33832321 .

7. Tepper DL, Burger AP, Weissman MA. Hands down, COVID-19 will change medical practice. Am J Manag Care 2020;26:e274e275. https://doi.org/10.37765/ajmc.2020.88478 (PMID: 32930555).

8. Crespo J, Fernández Carrillo C, Iruzubieta P, Hernández-Conde M, Rasines L, Jorquera F, et al. Massive impact of coronavirus disease 2019 pandemic on gastroenterology and hepatology departments and doctors in Spain. J Gastroenterol Hepatol. 2020;36:1627-1633. https://doi.org/10.1111/jgh.15340. Online ahead of print. J Gastroenterol Hepatol. 2020. PMID: 33184937

9. Coronavirus outbreak forces OUWB medical students to embrace 'new normal' in learning. Oakland University William Beaumont School of Medicine, Mar 24, 2020. Available at: https://oakland.edu/medicine/news/auto-list-news/2020/Coron avirus-outbreak-forces-OUWB-medical-students-to-embrace- $\%$ E2\%80\%98new-normal\%E2\%80\%99-in-learning. Accessed May 4, 2021.

10. Oakland University William Beaumont School of Medicine. Getting across the finish line: How OUWB keeps next-gen physicians on track during pandemic. Friday, May 01, 2020. Available at: oakland.edu/medicine/news/auto-list-news/2020/Getting-acrossthe-finish-line-How-OUWB-keeps-next-gen-physicians-on-trackduring-pandemic. Accessed May 4, 2021.

11. Centers for Medicare \& Medicaid Services. President Trump Expands Telehealth Benefits for Medicare Beneficiaries During COVID-19 Outbreak. CMS.gov, Mar 17, 2020 Available at: www. $\mathrm{cms}$.gov/newsroom/press-releases/president-trump-expands-teleh ealth-benefits-medicare-beneficiaries-during-covid-19-outbreak. Accessed April 14, 2020.

12. Mahadev S, Aroniadis OC, Barraza LH, Agarunov E, Smith MS, Goodman AJ, et al. Gastrointestinal endoscopy during the coronavirus pandemic in the New York area: results from a multiinstitutional survey. Endosc Int Open. 2020 Dec;8:E1865-E1871. https://doi.org/10.1055/a-1264-7599. Epub 2020 Nov 27.Endosc Int Open. 2020. PMID: 33269322.

13. Data obtained from William Beaumont Hospital endoscopy suite.

14. Gu J, Han B, Wang J. COVID-19: Gastrointestinal manifestations and potential fecal-oral transmission. Gastroenterology. $2020 \mathrm{Mar}$ 3. pii: S0016-5085(20)30281-X. https://doi.org/10.1053/j.gastro. 2020.02.054. [Epub ahead of print] No abstract available. PMID: 32142785 Accessed March 27, 2020.

15. AASLD, ACG, AGA, and ASGE. Gastroenterology professional society guidance on endoscopic procedures during the COVID-19 pandemic. Available at: info@gisocieties.org . Accessed May 4, 2021.

16. Cappell MS. Novel modifications for a virtual interview visit to simulate the traditional, live, site visit for GI fellowship applicants for an academic GI fellowship program due to the COVID-19 pandemic. Dig Dis Sci. 2021 Apr;66:1370-1371. https://doi.org/ 10.1007/s10620-020-06741-1. Epub 2021 Jan 26. Dig Dis Sci. 2021. PMID: 33496874

17. Amadeo, Kimberly. How COVID-19 has affected the US economy. The Balance. Updated February 24, 2021. Available at: https://www.thebalance.com/how-covid-19-has-affected-the-useconomy-5092445. Accessed April 30, 2021.

18. Udalova, Victoria. Pandemic impact on mortality and economy varies across age groups and geographies. United States Census, March 8, 2021. Available at: www.census.gov/library/stori es/2021/03/initial-impact-covid-19-on-united-states-econo my-more-widespread-than-on-mortality.html. Accessed May 4, 2021.

19. Beaumont News Releases. COVID-19 pandemic affects Beaumont Health's year-end 2020 financial results. Released February 15, 2021. Available at: www.beaumont.org/health-wellness/pressreleases/covid-19-pandemic-affects-beaumont-healths-year-end2020-financial-results. Accessed May 4, 2021.

20. Anonymous. Beaumont Health temporarily laying off 2,475 employees, permanently eliminating 450 jobs. Fox 2, Detroit. Available at: www.fox 2 detroit.com/news/beaumont-health-tempo rarily-laying-off-2475-employees-permanently-eliminating-450jobs. Accessed April 22, 2020.

21. Cavitt M. Beaumont lays off 2,475 employees, eliminates 450 jobs as major revenue streams dry up. Available at: www.theoa klandpress.com/news/beaumont-lays-off-2-475-employees-elimi nates-450-jobs-as-major-revenue-streams-dry-up/article_b5a5c 8d2-83d0-11ea-a90e-efa0ffcac378.html Oakland Press April 21, 2020. Accessed April 22, 2020.

22. Livengood C. Beaumont lays off 2,475 employees, eliminates 450 jobs as major revenue streams dry up. Crain's Detroit Business News, April 21, 2020. Available at: www.crainsdetroit.com/ health-care/beaumont-lay-2475-employees-eliminate-450-jobscut-executive-pay. Accessed April 23, 2020.

23. LeBlanc B., Henry Ford Health to furlough 2,800 employees amid COVID-19 losses. Detroit News, April 22, 2020. www. detroitnews.com/story/news/local/michigan/2020/04/22/henryford-health-furlough-2800-employees-amid-pandemic-losses/ 3008570001. Accessed April 23, 2020.

24. Carey M. Second week of HPI polling shows dentists' response to COVID-19: Four in five dentists closed their practices except for emergencies. ADA (American Dental Association News). Available at: https://www.ada.org/en/publications/ada-news/2020-archi ve/april/second-week-of-hpi-polling-shows-dentists-response-tocovid-19. Accessed April 25, 2020.

25. Kovanis, George. Trying to retain health care workers in times of COVID-19, Beaumont gives \$1,000 bonus. Detroit Free Press November 12, 2020. Available at www.freep.com/story/news/ local/michigan/2020/11/12/coronavirus-covid-19-beaumonthealth-employee-bonus/6266431002/. Accessed April 27, 2021

26. Beaumont Health offering walk-in COVID-19 vaccine clinic Thursday in Southfield. WWJ Newsradio 950. Local news. April 21, 2021. Available at: www.audacy.com/wwjnewsradio/news/ local/beaumont-opens-walk-in-vaccine-clinic-thursday-in-south field. Accessed May 4, 2021.

27. Napoli, N. COVID-19 pandemic indirectly disrupted heart disease care. January 11, 2021. Available at: www.acc.org/aboutacc/press-releases/2021/01/11/16/40/covid19-pandemic-indir ectly-disrupted-heart-disease-care. Accessed May 4, 2021.

28. Banerjee A, Chen S, Pasea L, Lai AG, Katsoulis M, Denaxas S, et al. Excess deaths in people with cardiovascular diseases during the COVID-19 pandemic. Eur J Prev Cardiol. 2021 Feb 21;zwaa155. https://doi.org/10.1093/eurjpc/zwaa155. Online ahead of print. PMID: 33611594.

29. Dixon, Jennifer. Coronavirus blamed in death of 37 -year-old doctor, father of three. Detroit Free Press April 10, 2020 6:38 p.m. ET. Available at: www.freep.com/story/news/local/2020/04/10/ coronavirus-covid-19-doctor-chris-firlit-wayne-state-university/ $5125851002 /$

30. Cappell MS. Moderately severe diarrhea and impaired renal function with COVID-19 infection. Am J Gastroenterol. 2020;115:947-948. PMID: 32453058 DOI: https://doi.org/10. 14309/ajg.0000000000000681

31. Gill I, Shaheen AA, Edhi AI, Amin M, Rana K, Cappell MS. Novel case report: A previously reported, but pathophysiologically unexplained, association between collagenous colitis and protein-losing enteropathy may be explained by an undetected link 
with collagenous duodenitis. Dig Dis Sci. 2021 Feb; 4:1-8. https:// doi.org/10.1007/s10620-020-06804-3. Online ahead of print. Dig Dis Sci. 2021. PMID: 33537921

32. Cappell MS. Problems for gastrointestinal patients with diarrheal disorders: Limited access to public bathrooms because previously open public bathrooms have closed due to COVID-19 pandemic and inadequate number of bathrooms in some endoscopy suites. Am J Gastroenterol. 2021;116:1355-1356. https://doi.org/10. 14309/ajg.0000000000001082.

33. Tingley K. Coronavirus Is Forcing Medical Research to Speed Up. New York Times Magazine, April 21, 2020. Available at: www. nytimes.com/2020/04/21/magazine/coronavirus-scientific-journ als-research.html Accessed April 25, 2020.

\section{Authors and Affiliations}

\section{Mitchell S. Cappell ${ }^{1,2}$ D}

\section{Mitchell S. Cappell}

Mitchell.Cappell@Beaumont.edu; mscappell@yahoo.com

1 Division of Gastroenterology \& Hepatology, William Beaumont Hospital at Royal Oak, 3535 West Thirteen Mile Road, MOB \#602, Royal Oak, MI 48073, USA
34. Available at: www.hpnonline.com/events/event/21202555/diges tive-disease-week-ddw-virtual. Accessed April 27, 2021.

35. Reuters Staff. Fact check: Outdated video of Fauci saying "there's no reason to walking around with a mask". October 8, 2020. Available at: https://www.reuters.com/article/uk-factcheck-faucioutdated-video-masks/fact-checkoutdated-video-of-fauci-saying-theres-no-reason-to-be-walking-around-with-a-mask-idUSK BN26T2TR. Accessed June 4, 2021.

Publisher's Note Springer Nature remains neutral with regard to jurisdictional claims in published maps and institutional affiliations.

2 Oakland University William Beaumont Hospital School of Medicine, 3535 West Thirteen Mile Road, MOB \#602, Royal Oak, MI 48073, USA 